\title{
Nobleza territorial y política ciudadana en el siglo XV (los concejos del área del Tajo)*
}

\author{
Territorial Nobility and Council Politics in the Fifteenth Century: \\ the Town Councils of the Tagus River Basin
}

\author{
José MARÍA SÁnCHEZ BeNITO**
}

\begin{abstract}
RESUMEN
En el estudio de las ciudades medievales no es raro que la nobleza territorial quede relativamente en penumbra, llegando incluso a entenderla ajena al sistema urbano. Sin embargo, una mirada simplemente superficial descubre con facilidad que su presencia en la vida ciudadana era muy considerable y así se ha destacado ya en varias investigaciones. Además, es tan grande la complejidad que presenta el influjo de los nobles en la misma que parece oportuno profundizar en los distintos papeles que efectivamente desempeñan y, al mismo tiempo, recapitular la problemática desde una perspectiva comparativa. Así pues, para alcanzar tales objetivos, recurriremos a la observación de los núcleos situados en el centro del reino castellano, a lo largo del río Tajo.
\end{abstract}

\section{PALABRAS CLAVE}

Nobleza, ciudades, concejos, estructuras de poder, sociedad urbana, Castilla, siglo XV.

\begin{abstract}
In research concerning medieval towns, it is not unusual for the territorial nobility to be neglected as a political player, even to the point of being considered an outsider to the urban system. However, even a quick view will easily reveal its considerable presence in municipal life, as previously demonstrated in various studies. Furthermore, the complex nature of the presence of the nobility is so great that it becomes essential to delve into the different roles they played, as well as review the issue from a comparative standpoint. Hence, in order to accomplish this task we will focus on the analysis of various town councils in the heart of the Kingdom of Castile along the Tagus river basin.
\end{abstract}

\section{KEY WORDS}

Nobility, Towns, Councils, Power Structures, Urban society, Castile, Fifteenth century.

\footnotetext{
* Fecha de recepción del artículo: 2013-04-10. Fecha de aceptación del artículo: 2013-11-05.

* Universidad Autónoma de Madrid. C.e.: josemaria.sanchez@uam.es

(Este artículo se ha realizado en el marco del proyecto «Fundamentos de identidad política: la construcción de identidades políticas urbanas en la Península Ibérica en el tránsito a la Modernidad», financiado por la Dirección General de Investigación y Gestión del Plan Nacional de I+D+i, referencia HAR 2009-08946.)
} 


\section{INTRODUCCIÓN}

Es un hecho cierto que el estudio de las ciudades de la Corona de Castilla se ha desarrollado extraordinariamente en las últimas décadas. Han contribuido a ello buena cantidad de trabajos de diversa índole y, como es lógico, tan cuantiosa actividad investigadora se ha orientado a través de distintas líneas, a fin de abordar unas realidades urbanas que presentan múltiples dimensiones. En tan variado panorama, los enfoques sistémicos, desarrollados desde los años ochenta, han permitido observar la «urdidumbre» —en expresión de Paulino Iradiel ${ }^{1}$ — de factores de diversa índole - grupos sociales, instituciones, valores...- que conforman la evolución de las sociedades urbanas y los poderes que nacen de ellas. De este modo, hemos aprendido a comprender el poder en términos de relación, participando, en mayor o menor medida, múltiples protagonistas que compiten y se entrecruzan a través de equilibrios cambiantes ${ }^{2}$. Pero siempre, desde luego, poderes en plural ${ }^{3}$.

Que esto es así parece fuera de toda duda, pero también es verdad que el análisis de tan poliédrica realidad tiene unos condicionantes, y en primer lugar, como ocurre en cualquier estudio histórico, las fuentes a disposición de los investigadores. Entre ellas hay que destacar para nuestros fines las de origen municipal, pues si bien su volumen varía mucho entre unas localidades y otras, han servido como base principal para casi todas las aproximaciones a la problemática de la ciudad bajomedieval y, en particular, a la actividad política que en ellas tenía lugar. Lo que ocurre es que dichas fuentes privilegian a los protagonistas de la vida institucional de los concejos - regidores, etc.- y se centran en los temas que les competen, quedando en penumbra otros agentes de la vida urbana. Siempre los historiadores dependen de sus fuentes de información, con las posibilidades y flaquezas que presentan, como también dependen de tradiciones historiográficas que ponen el acento mucho más en unos elementos -institucionalización concejil, oligarquías urbanas, incidencia de la monarquía- que en otros. De esta manera, con frecuencia se ha tendido a ocultar a los nobles territoriales, entendiendo que son ajenos al sistema urbano, sea por considerarlos meros rivales cuyos actos se oponen a la consolidación de dicho sistema y de los grupos socia-

1 IRADIEL MURUGARREN, P., «Formas del poder y de organización de la sociedad en las ciudades castellanas de la Baja Edad Media», en Estructuras y formas del poder en la historia, Salamanca, 1991, p. 30.

2 HERNÁNDEZ BENÍTEZ, M., «Oligarquías: ¿con qué poder?», en Poderes intermedios, poderes interpuestos. Sociedad y oligarquías en la España Moderna, Cuenca, 1999, p. 23, indica que el poder se debe contemplar como una relación en la que debemos identificar los actores, los intereses en juego y los medios para su ejercicio. Habla de equilibrio nunca permanente GUERRERO NAVARRETE, Y., «Rey, nobleza y élites urbanas en Burgos (siglo XV)», en El contrato político en la Corona de Castilla. Cultura y sociedad política entre los siglos X y XVI, Madrid, 2008, p. 242.

3 Pues si la atención de la mayoría de los estudiosos se ha centrado en el concejil, éste ni es el único ni es monolítico, tal como señalan MARTÍN CEA, J. C. y J. A. BONACHÍA, «Oligarquías y poderes concejiles en la Castilla bajomedieval: balance y perspectivas», Revista d'Historia Medieval, 9, 1998 p. 30. 
les que le sirven de cimiento, sea porque insistiendo principalmente en las llamadas oligarquías ciudadanas los análisis centrados en las mismas relegan a los grandes nobles. Lo que ocurre, no obstante, es que en las ciudades realengas de la Corona de Castilla, a poco que se avance en la lectura de la documentación disponible, salta a la vista la imposibilidad de negar la presencia e influjo de dichos nobles, que entre otras cosas tenían en ellas su residencia principal. Así que no será baladí aclarar el papel que tienen en el mundo ciudadano, particularmente en lo que se refiere a su presencia en el poder. Por consiguiente, en las páginas que siguen se pretende recapitular esta problemática con perspectiva comparativa ${ }^{4}, y$ así detectar carencias y problemas, incitando a investigar sobre las relaciones nobleza/ciudad.

En el artículo que desarrollaremos a continuación vamos a abordar el estudio de los núcleos urbanos realengos que, siguiendo el río Tajo quedan comprendidos entre la cordillera Ibérica y la tierra de Talavera, y de norte a sur entre el Sistema Central y los Montes de Toledo y confines de La Mancha. Indudablemente, se trata de una zona que presenta un buen grado de urbanización, y que desde los procesos repobladores se organiza en gran medida a partir de los concejos que allí se fueron estableciendo en el siglo que va de la conquista de Toledo a la de Cuenca. Para empezar y sin alejarnos demasiado del siglo XV —en el cual centraremos nuestras pesquisas- conviene dedicar nuestro interés a la implantación de los linajes que en el período citado alcanzarán un grado de influencia política determinante en las ciudades realengas. Dicha implantación se desarrolla en el contexto de lo que llamamos nobleza nueva, afortunada propuesta de Salvador de Moxó ${ }^{5}$, asumida por la historiografía posterior de un modo que podríamos calificar canónico, aunque estudios posteriores hayan introducido no pocos matices.

\section{LOS LINAJES NOBILIARIOS DOMINANTES Y SU IMPLANTACIÓN EN LAS CIUDADES}

Se sabe que en el curso del siglo XIV irrumpen linajes muy destacados en la región que nos interesa. Me refiero, en particular, a Mendoza, Ayala, Silva, Acuña..., por no citar más que algunos que logran alzarse a los lugares más encumbrados de las localidades a las que llegan, bien sea desde el norte peninsular 0 de Portugal. Cabría destacar en primer lugar la personalidad, desde luego muy conocida, de Pedro González de Mendoza, que si ya recibió mercedes de Pedro I,

\footnotetext{
${ }^{4}$ Como punto de partida debe tenerse en cuenta necesariamente el artículo de DIAGO, M., «La participación de la nobleza en el gobierno de las ciudades europeas bajomedievales. Análisis comparativo", Anuario de Estudios Medievales (A. E. M.), 37/2, 2007.

${ }_{5}$ Entre otras publicaciones de este autor, recordemos "De la nobleza vieja a la nobleza nueva. La transformación nobiliaria castellana en la baja Edad Media", Cuadernos de Historia. Anexos de la revista Hispania, 3, 1960, y "La nobleza castellano-leonesa en la Edad Media. Problemática que suscita su estudio en el marco de una historia social", Hispania, 30, 1970.
} 
contará después con especial reconocimiento de Enrique II. De manera que la adecuada elección de las oportunidades políticas que se le fueron presentando y el consecuente apoyo regio le permitió formar un sólido patrimonio, cuyo rapidísimo incremento, al compás de la carrera política del personaje, termina plasmándose nada menos que en cuatro mayorazgos ${ }^{6}$. Este dato nos da idea de la magnitud de los haberes conseguidos en un plazo bastante breve. Por lo demás, todo esto se traduce en la obtención de rentas y derechos de verdadera amplitud en el núcleo urbano allí existente, Guadalajara. No es en absoluto ajeno a estos procesos el hecho de que dicho núcleo dependiera en estos tiempos de distintas personas reales ${ }^{7}$. Debe tenerse en cuenta, por último, que en la siguiente generación - la del almirante Diego Hurtado- quedaron perfectamente afirmadas las piezas fundamentales del despliegue señorial que con mucha lógica geográfica llevaron a cabo estos personajes. En este despliegue, a modo de gran arco que a través del Real de Manzanares se aproximaba por el oeste a la villa de Madrid, Guadalajara desempeñaba una función de gran importancia como nexo capaz de coordinar las células que integraban tan amplios territorios.

Si a continuación nos desplazamos a Toledo, volveremos a encontrar factores muy similares. Se ha llegado a decir que al acabar la guerra civil Enrique II decidió colocar en esta urbe a determinados linajes favorables, de suerte que la política local discurriese de manera conveniente al trono ${ }^{8}$. Así que el perfil político presenta una vez más particular importancia en lo que se refiere al arraigo de los grupos nobiliarios más importantes de las ciudades. Bien es verdad que el éxito en la constitución de los patrimonios en el caso de los linajes toledanos tendrá que ser bastante más lento que en el ejemplo que encontrábamos anteriormente, y por lo que muestra la documentación relativa a las familias Ayala o Silva sabemos que todavía era discreto al comenzar el siglo $\mathrm{XV}^{9}$. Consecuentemente, los primeros tienen que esperar a los años cuarenta de la centuria para poner los cimientos de lo que serán sus bastiones territoriales, y mientras ellos trataban de abrirse paso en tierra de Toledo hasta conseguir en 1470 el título condal de Fuensalida, el linaje rival, Silva, presenta un modelo diferente. Lo primero que se nota en este último es que la dispersión de sus intereses y cargos es muy grande, del mismo modo que su incidencia señorial en el área resulta bastante reducida, desembocando

${ }^{6}$ Al respecto, LAYNA SERRANO, F., Historia de Guadalajara y sus mendozas en los siglos XV y XVI, Guadalajara, 2. ${ }^{\text {a }}$ ed., 1993, I-1, p. 80. Sobre el desarrollo del linaje Mendoza es imprescindible la monografía de SÁNCHEZ PRIETO, A. B., La Casa de Mendoza hasta el tercer duque del Infantado (13501531), Madrid, 2001. No entraremos en los avatares de la herencia de Pedro González de Mendoza, pero dos de esos mayorazgos volvieron pronto a la línea principal y después se terminarán consolidando tres ramificaciones, que en su momento encontraremos en nuestro texto, sin perjuicio de que a lo largo del siglo XV surgiesen otras más.

7 Recuérdese, por ejemplo, que Aldonza de Ayala, segunda esposa del citado Pedro González recibió todas las rentas de la reina en Guadalajara. MIGNOT, C., «Evolución de la estructura jurisdiccional en la región alcarreña (Siglos XI-XV)», Hispania, XLVI/163, 1986, p. 258.

8 LÓPEZ GÓMEZ, O., Los RRCC y la pacificación de Toledo, Madrid, 2008, p. 32.

9 PALENCIA HERREJÓN, J. R., Ciudad y oligarquía de Toledo a fines del Medievo (1422-1522), Tesis doctoral, Universidad Complutense de Madrid, 1999, p. 223. 
también en un condado, pero en la villa alcarreña de Cifuentes, lejos de su ciu$\mathrm{dad}^{10}$. Obviamente, Toledo no es Guadalajara, sus dimensiones y complejidad eran infinitamente superiores, abrirse camino en este medio no era fácil e inevitablemente la progresión que se observa en las familias allí asentadas no podrá ser tan explosiva como hemos visto antes. Además, el proceso de señorialización en el territorio toledano presentaba peculiaridades derivadas de la propia configuración del mismo. Al mismo tiempo, tengamos en cuenta que la enorme importancia de Toledo pone de manifiesto una capacidad de atracción mucho mayor que otras ciudades, porque esa misma complejidad, ese constante entrecruzamiento de gentes e influencias que es inherente a toda gran ciudad, podía proporcionar buenas oportunidades. Pensemos que, además, Toledo era un núcleo decisivo para la monarquía.

Teniendo todo esto en cuenta, volvamos atrás en el tiempo para comprobar la cronología de estos procesos de enraizamiento. Antes de la mitad del siglo XIV ya encontramos en la Alcarria a Gonzalo Yáñez Mendoza, montero mayor de Alfonso $\mathrm{XI}$, que se casó con Juana Orozco, perteneciente a uno de los linajes más importantes, y no solo de Guadalajara porque sus repercusiones llegaban lejos. Es la generación anterior a Pedro González de Mendoza, a su vez casado en primeras nupcias con María Fernández Pecha, igualmente de la nobleza local ${ }^{11}$. Por lo tanto, lo que parece novedad, el afianzamiento mendocino en la Alcarria, no lo es tanto, porque lo que se produce es un amplio entronque con familias aristocráticas de la zona y es la verdad que tales entronques no son anecdóticos sino que permiten a los Mendoza - como a otros- abrirse paso en la sociedad y en las estructuras de poder de la región. A partir de aquí se va desarrollando con presteza una verdadera absorción tanto de territorios y otros elementos patrimoniales de aquellas familias locales, como también de prestigios e influencias, a favor de un clan, el de Mendoza, que Mitre ha calificado como «agresivo y oportunista en lo político y en lo moral» ${ }^{12}$.

Pocos años antes de que Gonzalo Yáñez Mendoza apareciera en la Alcarria, los Ayala lo hacían en Toledo, de suerte que la cronología de su irrupción es coincidente, como lo es también el establecimiento de enlaces matrimoniales similares

10 Al hilo de esta problemática consultar: FRANCO SILVA, A., El condado de Fuensalida en la Baja Edad Media, Cádiz, 1994; MOLÉNAT, J. P., «Formation des seigneuries tolédanes aux XIVème et XVème siècles", en Realidad e imágenes del poder. España a fines de la Edad Media, Valladolid, 1988; RIESCO DE ITURRI, M. B., «Propiedades y fortuna de los condes de Cifuentes: la constitución de su patrimonio a lo largo del siglo XV», En la España Medieval (E. E. M.), 15, 1992; PALENCIA HERREJÓN, J. R., Ciudad y oligarquía de Toledo... No dejaré en el tintero la obra de MOXÓ, S. de, Los antiguos señoríos de Toledo, Toledo, 1973, ni tampoco el libro importantísimo para todo lo concerniente al territorio toledano de MOLÉNAT, J. P., Campagnes et monts de Tolède du XIlème au XVème siècle, Madrid, 1997, cuyos contenidos se tendrán en cuenta en muchos puntos de este artículo.

11 Ver MIGNOT, C., «Evolución de la estructura jurisdiccional...», pp. 256-59. Muchos datos en la obra ya citada de SÁNCHEZ PRIETO, A. B., La Casa de Mendoza...

12 MITRE, E., «Marcos de actuación política y señas de identidad de la nobleza tardomedieval castellana», Wad-al-Hayara, 22, 1995, p. 12. 
a los que acabamos de ver. Se ha apuntado con acierto que la sangre local determina su arraigo toledano, exactamente igual que vimos antes en el caso de Guadalajara ${ }^{13}$. Si en muchas ocasiones se ha hablado de crisis de las familias nobiliarias preexistentes y se han alegado datos acerca de la extinción de la línea masculina de algunas o de las dificultades políticas de otras, a la luz de lo que estamos planteando aquí es preciso insistir en las continuidades. Estos enlaces vienen a mostrar que no hubo ruptura. A lo largo de estos años se produjo la llegada de otros personajes, cuyo empaque no alcanzará nunca a los anteriores pero que, enraizando en la zona, conseguían labrarse pequeños señoríos ${ }^{14}$ y terminarán constituyéndose en elementos de peso, aunque sea en un segundo nivel. Sirven de ejemplo los Niño, enlazando matrimonialmente con una familia local relevante - Tordelobos-, de la que derivan contactos, influencias, pero también -y no es caso único- recursos económicos ${ }^{15}$. Precisamente la capacidad para articular a estos linajes menores, que tienen señoríos y no pocos medios pero que nunca consiguen alzarse por encima de los demás, tendrá una gran importancia en el ascenso de los más brillantes. Si en este aspecto, como en tantos otros, la eficacia de los Mendoza alcarreños es extraordinaria, lo mismo comprobamos cuando se observan los movimientos de los Ayala toledanos y los que se producen en otros ámbitos de la región que todavía no han salido a relucir.

Uno de estos ámbitos es Huete, donde en la primera mitad del siglo XIV cabe recordar a Alonso Ruiz de Sandoval, procedente de Burgos y premiado con un señorío en el alfoz optense: La Ventosa ${ }^{16}$. No se incluye en las filas de la más alta nobleza pero podrá aprovechar las circunstancias y los momentos de debilidad de familias más poderosas para incrementar su ascendiente en esta ciudad. Con anterioridad estaba presente en esta comarca la familia Carrillo, cuyo desarrollo tiene lugar desde fines del siglo XIII en relación con Priego, donde por aquellas fechas el trono les hizo donación de los derechos reales y más tarde se formó el señorío. Durante el siglo XIV consiguieron avanzar en el panorama social y político, hasta llegar a obtener un enorme influjo en Huete -y en menor medida en Cuenca-, del que daremos razón más adelante y que se prolonga hasta la mitad del siglo XV.

Hay que esperar unos años, en el transcurrir del siglo XIV, para encontrarnos con otros troncos parentales que ya no son de procedencia norteña sino portuguesa, y cuya irrupción en nuestro panorama regional depende directamente de los

\footnotetext{
13 Insiste en la importancia de los matrimonios, MOLÉNAT, J. P., «La noblesse tolédane du XVe siècle et ses origines", en Les sociétés urbaines en France Méridionale et en Péninsule Ibérique au Moyen âge, París, 1991, pp. 212-15.

14 Tengamos presente que los señoríos se articulan en una «jerarquía compleja y articulada», P. IRADIEL, "Señoríos jurisdiccionales y poderes públicos a finales de la Edad Media», en Poderes públicos en la Europa medieval: Principados, reinos y coronas. 23 Semana de Estudios Medievales. Estella, Pamplona, 1997, p. 72.

15 FRANCO SILVA, A., «Los Niño. Un linaje de la oligarquía municipal de Toledo en el siglo XV», A. E. M., 31/1, 2001, pp. 193-96.

16 ORTEGA CERVIGÓN, J. I., «Un enclave nobiliario en la tierra de Huete: el señorío de La Ventosa durante el siglo XV», Lope de Barrientos. Seminario de cultura, 3, 2010.
} 
sucesos políticos que van pautando las difíciles relaciones con el reino portugués. Son los Silva en Toledo, los cuales vuelven a mostrar el adecuado matrimonio que permite establecer un cimiento local suficientemente sólido —en esta ocasión el de Arias Gómez de Silva con la hermana del arzobispo Pedro Tenorio-, iniciándose la configuración del patrimonio en la siguiente generación; y en el este - Cuenca y Huete- Lope Vázquez de Acuña, señor de Buendía en 1397, formándose en la inmediata generación dos ramas, una vinculada a Buendía y la otra dando muestras de una agresividad que seguramente responde a la escasez de su plataforma territorial ${ }^{17}$.

Pocos años antes había irrumpido en el panorama nobiliario conquense una rama de los Mendoza, cuando Juan Hurtado el Viejo, que entre otras cosas fue miembro del Consejo Real de Enrique III, se casó con María de Castilla, señora de Olmeda de la Cuesta. Aunando, como casi siempre, favor regio y matrimonio adecuado -en este caso porque proporcionaba un señorío y no tanto por arraigo local—, se formó un cimiento patrimonial cuya cabeza se situará en Cañete. En la siguiente generación el linaje emerge hasta hacerse imprescindible en toda la zona $^{18}$. No es marginal la importancia que en ello tuvo una vez más el matrimonio afortunado, esta vez de Diego Hurtado de Mendoza con Beatriz de Albornoz. En la segunda mitad del siglo XIV eran precisamente los sucesivos vástagos de la familia Albornoz los que en el ámbito conquense presentaban una mayor relevancia tanto en el plano económico como político y, por supuesto, señorial. Formaban sin la menor duda la cúspide nobiliaria y Beatriz de Albornoz reunía una parte importante de la herencia legada por su parentela. Se constituye así un conjunto señorial suficientemente compacto y muy adecuado para sacar beneficio de los principales recursos económicos de la zona. Alrededor de 1400 el panorama aristocrático se estaba transformando decisivamente en el ámbito conquense, de forma que la consolidación de la referida rama del gran conglomerado Mendoza les permitía asumir la supremacía que antes tuviera la familia Albornoz. Lo hacían recogiendo en parte su legado material y sumergiéndose en la sociedad local hasta alzarse con la influencia que aquellos habían tenido sobre ella. No podemos entrar en detalles sobre los procesos de señorialización que tienen lugar en estas tierras, pero no olvidaremos que su complejidad es grande y que tiene mucho que ver en ello la fragmentación del patrimonio albornociano.

17 ORTEGA CERVIGÓN, J. I., «El arraigo de los linajes portugueses en la Castilla bajomedieval: el caso de los Acuña en el obispado de Cuenca», Medievalismo, 16, 2006. El matrimonio del primer Lope Vázquez con Teresa Carrillo de Albornoz, señora de Paredes, Portilla y Valtablado, le emparentaba con la mejor nobleza local, proporcionando las correspondientes relaciones, influencias y proyección en el territorio.

${ }_{18}$ Un buen resumen sobre el proceso de consolidación del linaje en ORTEGA CERVIGÓN, J. I., «La acción política y la proyección señorial de los Hurtado de Mendoza en Cuenca y su tierra durante el siglo XV", II. ${ }^{\circ}$ y III. ${ }^{\circ}$ Premio de Investigación Juan Giménez de Aguilar, Cuenca, 2003, especialmente pp. 13-16. 
Hay una tercera rama Mendoza instalada en el área de Molina a consecuencia de las disposiciones testamentarias de Pedro González de Mendoza. En segunda generación esta rama se vinculó con el linaje Carrillo - cuyo despliegue en Huete ya conocemos- mediante el matrimonio de Teresa Carrillo con Diego Hurtado. Por ahora nos conformaremos con poner sobre el tapete que los sucesivos herederos Carrillo de Mendoza, mirando tanto hacia Cuenca como hacia Molina y con un punto de apoyo fundamental que es el condado de Priego, se constituirán también en protagonistas, aunque en un segundo plano, de la vida pública ciudadana ${ }^{19}$. Por lo tanto, las dos derivaciones Mendoza no se sitúan en un mismo nivel sino que aparecen claramente jerarquizadas, y asumen buena parte del significado que en Cuenca y Huete habían tenido los linajes autóctonos dominantes que han quedado mencionados.

Todos los linajes que hasta ahora hemos ido encontrando en las diferentes condiciones de Toledo, Guadalajara, Cuenca, Huete o Molina, tienen en común, entre otras cosas, que buscan la ciudad. Lo hacen con el mayor interés porque quieren residir en el medio urbano, también porque desean un centro económicamente activo para su patrimonio, e igualmente por las relaciones sociales y políticas que sólo en tales núcleos cabía establecer. La ciudad es para ellos una plataforma imprescindible que puede ofrecerles una proyección mucho más extensa que el alcance, por grande que sea, de sus señoríos, y les facilita enlazar con otros protagonistas de la vida pública. Los grandes ven en las ciudades $-\mathrm{y}$, en concreto, en la que les resultase más cercana- tales atractivos que se tornan imprescindibles. Es la verdad que necesitan para sus fines la centralidad que en todos los órdenes ejercen los núcleos urbanos en el territorio.

Avanzado el siglo XV, en una etapa claramente diferenciada de las anteriores y al compás del acontecer político, entra en escena algún otro personaje, como Diego Arias Dávila, miembro de una relevante familia segoviana, pero sobre todo contador mayor, secretario de Enrique IV y firme partidario de su causa, por cuyas mercedes construyó un apreciable patrimonio en el área madrileña. Sobre estas bases y siempre en contacto con la alta nobleza más próxima, será muy notable su papel en las relaciones políticas de la villa ${ }^{20}$. Por estos años, fue mayor el impacto que tuvo el obispo Lope de Barrientos en Cuenca, trastocando por completo la dinámica de la vida pública urbana y dejando después una descendencia que si bien fue capaz de ejercer cierto protagonismo en la misma, no podrá paragonarse con los linajes más sólidos y terminará absorbida ${ }^{21}$.

\footnotetext{
19 Ver QUINTANILLA RASO, M. C., «El condado de Priego de Cuenca. Un ejemplo de estrategia señorial en la Baja Edad Media castellana», Historia. Instituciones. Documentos (H. I. D.), 19, 1992.

20 VERA YAGÜE, C. M., «Los conflictos interjurisdiccionales como factor determinante de la organización espacial: Ios Arias Dávila frente al concejo de Madrid en el siglo XV», en Organización social del espacio en el Madrid medieval, II, Madrid, 1997, pp. 99-100.

21 Referencias a dicha descendencia, hijo y sobrino, en ORTEGA CERVIGÓN, J. I., La acción política y la proyección señorial de la nobleza territorial en el obispado de Cuenca durante la Baja Edad
} 
La última fase de los procesos de implantación que estamos siguiendo queda perfectamente representada por el ascenso de Gutierre de Cárdenas, literalmente de la mano de Isabel la Católica a cuyo círculo cortesano pertenecía. Tal ascenso se refleja en señoríos, títulos, riquezas y cargos, base más que suficiente para escalar hasta los primeros lugares de la sociedad política toledana. No es muy distinta la trayectoria de Andrés Cabrera, cuya progresión se inicia en la política cortesana de la época de Enrique IV, siguiendo después en la fidelidad a los Reyes Católicos. Recibió amplios señoríos, culminando en el marquesado de Moya, pero la presencia que tuvo a lo largo de su vida en Cuenca, su ciudad de origen, no es comparable a la que alcanzó en Segovia ${ }^{22}$. Así pues, lo que observamos en esta última etapa es el éxito de brillantes cortesanos, firmemente leales al lado del trono. Ahora bien, llegados a este punto no dejaré de destacar que el ascenso de todos los linajes anteriormente mencionados - y no solo los citados al final- tiene lugar inequívocamente en el seno de las estructuras de la monarquía, en las condiciones de conflictividad y débil estatalización ${ }^{23}$ que son propias de la época y que explican muchos de los comportamientos que veremos en este trabajo.

Así que hasta ahora hemos visto que para la consolidación de los linajes mencionados en las ciudades y sus ámbitos de influencia coinciden unos factores que principalmente son los siguientes: a) favor del rey, b) aprovechamiento de las oportunidades políticas que a cada uno se fueron presentando, c) posicionamiento en las redes sociales existentes en los núcleos urbanos, d) enlaces matrimoniales adecuados para ello, e) obtención de señoríos. Todo indica que estos factores son totalmente imprescindibles si se quería tener la base adecuada para adquirir un grado elevado de protagonismo político. Habría que añadir el rápido crecimiento del patrimonio material —dejando ahora a un lado los señoríos-, imprescindible para algunos autores ${ }^{24}$ y que se hace recurriendo a compras - a veces a gran velocidad-, herencias u otra clase de negocios jurídicos, cuya frecuencia se ve facilitada por la carrera política del interesado, así como por las relaciones familiares y la liquidez que proporcionaban rentas y sueldos del rey. Frecuentemente se evidencia que tampoco se desdeñaban las vías ilegales si eran útiles para incrementar las adquisiciones, especialmente en algunos casos. Después, cuando a lo largo del tiempo se alcanzaban posiciones de supremacía política local, tal cosa se traducía en unas excelentes oportunidades para el incremento de la fortuna.

Media, Tesis doctoral, Universidad Complutense de Madrid, pp. 206-08. Es significativo que su hijo se casara con María de Mendoza.

22 PALENCIA HERREJÓN, J. R., «Estrategia patrimonial y jerarquía del linaje: los mayorazgos de la casa ducal de Maqueda en el s XVl», H. I. D., 29, 2002, pp.340-41 y, del mismo autor, Ciudad y oligarquía de Toledo a fines del Medievo..., p. 230. Ha dedicado atención a Andrés Cabrera RÁBADE OBRADÓ, M. P., Una élite de poder en la Corte de los Reyes Católicos. Los judeoconversos, Madrid, 1993, pp. 173-226.

${ }^{23}$ Llama la atención a este respecto IRADIEL MURUGARREN, P., «Señoríos jurisdiccionales y poderes públicos a finales de la Edad Media...", p. 103.

${ }^{24}$ M. C. QUINTANILLA ha destacado que el predominio de los nobles en las ciudades realengas tenía en la adquisición de tierras e inmuebles uno de sus soportes. "Reflexiones sobre los intereses nobiliarios y la política regia en torno a Huete en el siglo XV», A. E. M., 1989, p. 439. 
Viene a ejemplificarlo, aunque de una manera acaso extrema, Lope Vázquez de Acuña, cuando desde la fortaleza de Huete se impuso sin paliativos en esta ciudad y valiéndose de su fuerza realizó toda clase de usurpaciones y contratos abusivos, exigió censos sin justificación y adquirió por cualquier medio toda clase de recursos ${ }^{25}$. Al afianzamiento patrimonial contribuía de manera no despreciable la propiedad ganadera, de tanta importancia en la región que estamos estudiando ${ }^{26}$, así como los derechos de aprovechamiento de los comunales realengos que los nobles tenían en su condición de vecinos de un núcleo urbano y, a veces — sin necesidad de la vecindad-, en virtud del prestigio personal. En todo caso, las políticas e intereses patrimoniales varían bastante entre unos linajes y otros, sin que quepa imaginar que a la larga tuviesen siempre éxito.

No es este el lugar para profundizar en las características que presentan las referidas propiedades, así que inmediatamente trasladaremos nuestra atención a otras cuestiones. Sólo una cosa antes de terminar. Aunque todos se preocuparon siempre por adquirir inmuebles de diversa índole en los núcleos ciudadanos, parece cierto que los grandes de Toledo incluían en sus patrimonios una mayor proporción de tales casas, solares e infraestructuras, lo cual redunda en la naturaleza profundamente urbana que tenían ${ }^{27}$. En este sentido, hay que poner en primer plano los palacios que fueron levantando en las ciudades los personajes que han ido surgiendo al hilo de nuestra narración. Entiéndase que su construcción es característica de la nobleza implantada en las urbes castellanas y por descontado que entre las funciones de estos edificios no hay que ver sólo las meramente residenciales. Eran centros de actuación y verdaderos símbolos de las grandes familias. Además, por su volumen y calidad constructiva, se incorporaron, como parte esencial, a la imagen urbana, e incluso, me atrevería a decir, al honor de la ciudad $^{28}$.

${ }^{25}$ SÁNCHEZ BENITO, J. M., Ciudad, territorio y poder: Huete y sus aldeas en el siglo XV, Cuenca, 2006, particularmente p. 218. Sobre este linaje ver el artículo ya citado de ORTEGA CERVIGÓN, J. I., «El arraigo de los linajes portugueses en la Castilla bajomedieval...».

${ }^{26}$ Un estudio centrado en la parte más oriental de la región objeto de estudio es el de QUINTANILLA RASO, M. C., «El pastoreo en Cuenca a fines de la Edad Media. Bases y lógicas de un sistema económico en la compleja realidad agraria", en Los rebaños de Gerión. Pastores y trashumancia en Iberia antigua y medieval, Madrid, 2001.

${ }_{27}$ Se sabe, por poner un ejemplo, que Juan de Silva tenía un gran número de inmuebles en las collaciones toledanas de San Román y San Salvador durante la época de los Reyes Católicos, PALENCIA HERREJÓN, J. R., Ciudad y oligarquía de Toledo..., p. 227.

${ }^{28}$ Es interesante el artículo de MOLÉNAT, J. P., «En busca de los palacios urbanos de la nobleza toledana del siglo XV a través de la documentación escrita", en La ciudad medieval: de la casa al tejido urbano, Cuenca, 2001. Insistiendo en la importancia de estos palacios, aporta más detalles el trabajo del mismo autor "La noblesse tolédane du XVe siècle et ses origines", pp. 205-08. Ver también IBÁÑ̃EZ MARTíNEZ, P. M., Arquitectura y poder. Espacios emblemáticos del linaje Albornoz en Cuenca, Cuenca, 2003. Ciertos datos sobre residencias nobiliarias en esta ciudad en mi libro El espacio urbano de Cuenca en el siglo XV, Cuenca, 1997, pp. 20 a 24. Cabe recordar que muchos miembros de la alta nobleza contaban con residencia en más de una ciudad. Su relevancia personal en cada una de ellas es variable pero, en cualquier caso, estas construcciones siempre tienen valor como respaldo de la proyección de sus propietarios allí donde se edifican. 
Otro aspecto esencial en los procesos de consolidación nobiliaria es la cohesión y amplitud de los linajes llamados a tener un mayor peso específico. Una vez más son los Mendoza los que llevan al máximo estas características, pero también se nota una sólida cohesión en todos los que alcanzaron posiciones dominantes en Toledo y Cuenca. Esta constatación no nos hace olvidar que en el interior de cada uno de ellos y a lo largo de la sucesión de herencias y aconteceres políticos no faltaron ocasiones para la proliferación de odios. Era relativamente habitual que los peor colocados en la línea hereditaria intentasen mejorar su caudal mediante el pleiteo y a veces las diferencias conducían a graves enfrentamientos que llegan a revestir dimensiones bélicas y dan lugar a episodios dramáticos ${ }^{29}$. En todo caso, cohesión, tamaño, capacidad para aglutinar y para mantener una acción política sostenida, son caracteres relevantes que hemos de retener.

En definitiva, sin ánimo de entrar en la complejidad de las sociedades urbanas y simplificando las cosas, resulta que en cada una de las ciudades objeto de nuestro interés hay unos linajes que se alzan hasta ocupar la cúspide de la pirámide política, aunque sea en competencia - a veces eterna- con otros. Al mismo tiempo, se puede observar en un segundo plano una nobleza, igualmente territorial, cuya capacidad de acción en los asuntos públicos es inferior y en buena medida se ejerce en relación con los principales. Todos se insertaban en la complejísima red de vinculaciones que articulaba la sociedad urbana, pero de tal manera que los más importantes tenían capacidad para trastocar dicha red al actuar como focos alrededor de los cuales se orientan muchos de los vectores que conforman las relaciones de poder. En fin, hasta aquí no hemos hecho otra cosa que exponer las piezas con que contamos para avanzar hacia nuestro objetivo, esto es, el impacto de la nobleza territorial en la política ciudadana.

\section{LAS DINÁMICAS POLÍTICAS}

Al comienzo del siglo XV la escasa afirmación de la élite urbana y, al mismo tiempo, las tensiones existentes entre pecheros y exentos, definen el contexto en el cual el almirante Diego Hurtado ejerce la más completa supremacía en Guadalajara, incluyendo el control de los cargos municipales. Acaso la consolidación de esta superioridad y las alteraciones que tal cosa comportaba en la articulación de la sociedad, contribuían en no poca parte a tales desequilibrios. En todo caso, la ausencia física del noble, si se prolongaba en el tiempo, permitía que las diferencias en torno a la gobernación concejil saliesen con brío a la superficie. Es lógico, por tanto, que su temprana muerte tuviese consecuencias debilitando la posición dominante del linaje, ahora encabezado por su sucesor Î́nigo López, y recrude-

${ }^{29}$ Ver ORTEGA CERVIGÓN, J. I., «Crónica de un fratricidio: el linaje Carrillo de Albornoz en la tierra de Cuenca durante la Baja Edad Media», en Castilla y el mundo feudal. Homenaje al profesor Julio Valdeón, Valladolid, 2009, I. 
ciendo unas tensiones ciertamente encubiertas pero nunca eliminadas por el orden que el almirante había impuesto. Por lo tanto, no podrá sorprender que en 1420 las diferencias internas de la propia familia Mendoza - concretamente, entre ínigo López y su hermana Aldonza- encuentren reflejo en las calles en forma de allegamientos de gentes armadas del lado de uno y otra.

Los problemas que surgen en estos años ponen de manifiesto las dificultades de una forma de gobernar que tenía unos componentes personales nada despreciables pero que, a pesar de todo, nunca se pondrá en cuestión. Hay que esperar a 1459, muerto poco antes el citado ínigo López, y en el marco del enfrentamiento que por entonces oponía al linaje Mendoza con el marqués de Villena, para que tropas enviadas por el soberano se hiciesen cargo de Guadalajara, expulsando a los que habían estado a su frente durante decenios. Tiene gran protagonismo en estos hechos el alcaide de la fortaleza, totalmente apartado de las redes mendocinas, y no faltó el apoyo de familias locales que con el cambio pensaban salir ganando. Sin embargo, no hubo verdadera transformación sino que se trataba de un episodio más de la pugna política del reino y, en particular, del choque entre los intereses de Mendoza y Pacheco. Guadalajara era la prenda de una negociación entre ambos ${ }^{30}$.

La localidad, también alcarreña, de Huete presenta varios puntos en común aunque el discurrir de los equilibrios internos resulte en ella mucho menos monocorde. En principio, situándonos de nuevo en el comienzo del siglo XV, el contexto es similar a lo que vimos en Guadalajara —escasa afirmación de la élite y tensiones entre exentos y pecheros-. La villa había sido entregada a Constanza, hija mayor de Pedro I, y después a su hija Catalina, y en esas condiciones la familia Carrillo - contando con su señorío de Priego- se abre camino hasta afianzarse a la cabeza del sistema político local. Pedro Carrillo, llamado de Huete, representa perfectamente esta situación. En realidad, su ascendiente en la vida pública local es determinante, a través de sus bases patrimoniales, su cercanía personal al rey -que le permite obtener favores para sí mismo y, al mismo tiempo, para la ciudad- y el control de resortes de poder de tanta importancia como la guarda mayor, la alcaldía de las alzadas y la arriscada fortaleza. A su muerte, el linaje pierde

${ }^{30}$ Los datos proceden de las siguientes publicaciones: LAYNA SERRANO, F., Historia de Guadalajara y sus mendozas...; LÓPEZ VILLALBA, J. M., «Concejo abierto, regimiento y corregimiento en Guadalajara (1346-1546)", en Espacio, Tiempo y Forma. Historia Medieval (E.T. F.), 5, 1992; LÓPEZ VILLALBA, J. M., «El cuaderno de condiciones del común de Guadalajara de 1405», E. T. F., 3, 1990: MIGNOT, C. "Le 'municipio' de Guadalajara au XVême siècle, système administratif et économique (1341-1567)", $A$ E. M., 14, 1984. Nada más lejos de nuestra intención que entrar en los vericuetos de la política castellana en la segunda mitad del siglo XV, lo importante es que permitió a nuestros protagonistas obtener importantísimas prebendas y que Guadalajara se convirtió para ellos en baza principal para sostener los intereses linajísticos. La trayectoria política del linaje Mendoza en SÁNCHEZ PRIETO, A. B., La Casa de Mendoza..., pp. 51-167. Sobre los acontecimientos del reino pueden consultarse las obras de SUÁREZ FERNÁNDEZ, L., Nobleza y monarquía. Puntos de vista sobre la historia política castellana del siglo XV, Valladolid, 1975, y «Los Trastámaras de Castilla y Aragón en el siglo XV», en Historia de España. Ramón Menéndez Pidal, Madrid, 1970, XV. 
la continuidad de su línea principal y se abre espacio para otros que desde niveles inferiores también trataban de abrirse paso en la zona. De este modo, los Sandoval, contando con el señorío de La Ventosa, consiguen obtener el cargo de guarda mayor, aunque a la postre será Lope Vázquez de Acuña, casado con una hija de Pedro Carrillo, el que se imponga. Escaso en señoríos y perdidas las posibilidades de influir en la ciudad de Cuenca, pero contando con el castillo optense, Lope Vázquez se inclinó decididamente por la acción política de manos del arzobispo Carrillo, y desde la plataforma que le ofrecía la fortaleza interviene en los conflictivos aconteceres de la época de Enrique IV. Cuando, según disposición testamentaria de Juan II, la ciudad se convierte en señorío del príncipe Alfonso, el marqués de Villena le encargó que se ocupase de la toma de posesión y se le confirmó la fortaleza por juro de heredad. La presencia allí de Acuña aseguraba al marqués una posición muy importante y Lope Vázquez se aprovecha ejerciendo una dominación sin paliativos. Es un ejemplo de intervención absorbente en los más diversos aspectos de la vida local. Ni que decir tiene que, entre otras cosas, el cargo de guarda mayor pasó a sus manos, en perjuicio de los ya mencionados Sandoval. Tras la victoria de los Reyes Católicos, Lope Vázquez de Acuña obtiene el perdón, pero pierde el control de Huete y, por supuesto, de su castillo. Alejo de Sandoval esgrimirá —no sin dificultades- sus derechos a la guarda mayor y Juan Osorio, a las órdenes de los soberanos, reunirá los cargos de corregidor y alcaide del castiIlo, intentando abrirse un hueco en el entramado político local ${ }^{31}$.

Si hasta ahora hemos encontrado situaciones de claro predominio por parte de determinados nobles, Molina podría ser el contrapunto, pues si no falta un linaje que con continuidad trata de realizar sus aspiraciones en tal sentido, es la verdad que nunca logra consolidar sus deseos. En esta villa debemos fijarnos muy especialmente en la poderosa fortaleza, en manos de Diego Hurtado de Mendoza desde las últimas décadas del siglo XIV y después de la rama molinesa de esta familia, más tarde condes de Priego. Sin duda, la solidez del castillo ponía en sus manos una palanca política de primer orden. Pero hay un segundo dato que contrarresta en buena parte la influencia que desde allí podían ejercer los Mendoza molineses. Me refiero a la inestabilidad que mostraron sus dominios señoriales en aquella tierra. Esta importante dificultad les impedirá consolidar sus posibilidades de dominio en la política de la villa, al tiempo que abría la puerta al ascenso de un personaje local, Juan Ruiz de Molina, que actúa desde el regimiento. Contra él hubo que disputar señoríos, influencias y, en definitiva, el poder, formando alrededor de cada uno los correspondientes bandos. Inevitablemente, la pugna afectó seriamente a la tierra y se mantuvo tras la muerte de los primeros protagonistas,

${ }^{31}$ Me he apoyado en los siguientes trabajos de QUINTANILLA RASO, M. C., La ciudad de Huete y su fortaleza a fines de la Edad Media, Cuenca, 1991; «Huete, la patria del Halconero, a fines de la Edad Media», I Congreso de Historia de Castilla La Mancha, VI, Toledo, 1988; «Reflexiones sobre los intereses nobiliarios y la política regia en torno a Huete en el siglo XV». Mi monografía sobre esta localidad, cuyo título es Ciudad, territorio y poder..., presenta el marco general y se refiere a las estructuras de poder de la ciudad y tierra. 
el mencionado Juan Ruiz de Molina y el primer conde de Priego. Después las cosas se complicaron, los descendientes del primero se afianzaron en el regimiento e irrumpieron nuevas fuerzas durante los años rotos del reinado de Enrique IV. En 1465 la villa fue cedida en señorío a Beltrán de la Cueva, muchos se opusieron y los bandos se reestructuraron de esta suerte. A la postre, el arzobispo Carrillo se hizo con la fortaleza, formando tras él otros miembros de su familia, y hasta bien entrados los años de los Reyes Católicos aparecen como un factor condicionante de la vida local ${ }^{32}$. Lógicamente, los condes de Priego siguieron defendiendo lo que creían sus derechos en lo tocante a rentas y señoríos, pero en un panorama en el cual estaban lejos de ocupar lugares determinantes ${ }^{33}$.

Así pues, Molina presenta unas características diferentes a los casos anteriores. La alta nobleza está presente en muchos aspectos de la vida local e incide de manera muy importante en la política que allí se desarrolla, pero no puede hacerse con el control al modo de Guadalajara o de Huete. En estas dos localidades no falta la pugna por el poder, porque es inherente al propio sistema, pero Molina nos permite tomar contacto de un modo muy vivo con la pugna de bando ${ }^{34}$, cuya expresión más clara se observa en Toledo y Cuenca. A ambas ciudades prestaremos atención ahora sabiendo de antemano que ofrecen un modelo en el que determinados linajes nobiliarios sostienen sus pretensiones de predominio de manera continuada en el tiempo y con mucho más éxito que los Mendoza molineses, pero, eso sí, en confrontación casi eterna.

Cuando se inician las actas municipales conquenses en el año 1417, el panorama que encontramos no puede ser más duro. Había en la ciudad dos bandos claramente establecidos, a la cabeza de los cuales figuraban Lope Vázquez de Acuña - padre del personaje de igual nombre antes citado- y Diego Hurtado de Mendoza. El choque, que arranca de tiempo atrás, no tiene otro objeto que dominar la ciudad, aunque para ello hubiese que inundar sus calles con la violencia de los muchos allegados de uno y otro. Como es habitual en estos conflictos, la coro-

${ }^{32}$ Para el caso de Molina ver CORTÉS RUIZ, M. E., Articulación jurisdiccional y estructura socioeconómica de la comarca de Molina de Aragón a lo largo de la Baja Edad Media, Tesis doctoral, Universidad Complutense de Madrid, 2000; y DIAGO, M., «Relaciones de poder y conflictos políticos en Molina y su tierra durante el reinado de los Reyes Católicos», Wad al-Hayara, 20, 1993.

${ }_{33}$ QUINTANILLA RASO, M. C., «Estructuras y relaciones de poder en la tierra de Cuenca a fines de la Edad Media», en La Península Ibérica en la era de los descubrimientos, 1391-1492. Actas de las II Jornadas Hispano-Portuguesas de Historia Medieval, Sevilla, 1991, p. 717. Ahora bien, en el caso molinés es imprescindible tener presente la influencia, aunque sea indirecta, de los condes de Medinaceli, inmediatamente reflejada en la escisión a su favor de determinados lugares de la extensa tierra de la viIla. Los mismos condes de Medinaceli ejercieron similar influencia en Cuenca e incluso en Guadalajara así como los marqueses de Villena en Toledo y Cuenca. Esta clase de influjo indirecto es importante en Madrid, esta vez a cargo de los marqueses de Santillana desde Guadalajara.

${ }_{34}$ También en Madrid tuvieron lugar pugnas de bandos nada despreciables, que se ven claramente en la guerra que tuvo lugar al comienzo del reinado de los Reyes Católicos. Al frente de los bandos figuran señores de vasallos de segundo nivel, afincados en los órganos de gobierno de la villa y convenientemente enlazados con los marqueses de Santillana o de Villena. Una monografía extensa sobre Madrid es la de LOSA CONTRERAS, C., El concejo de Madrid en el tránsito de la Edad Media a la Edad Moderna, Madrid, 1999. 
na intervino con medidas de tregua y expulsión de los contendientes fuera del recinto urbano. Al mismo tiempo, desde la institución concejil se intentaba negociar y, sobre todo, afirmar la propia identidad municipal. En 1419 uno de los implicados, Diego Hurtado, recibió del rey la dignidad de guarda mayor de la urbe, obteniendo así una ventaja indiscutible. El rango recién adquirido suponía un reconocimiento del soberano y una ventaja táctica de primera magnitud, en virtud de la posición jerárquica y las funciones, mejor o peor definidas, que el mismo otorgaba. Sin embargo, la pugna permaneció viva, como siguieron vigentes los bandos, al punto que en unos voluntariosos capítulos el corregidor llega a afirmar que nadie sostenía la voz del rey y todos los vecinos estaban del lado de Mendoza o de Acuña. De este modo, la inseguridad siguió por lo menos hasta 1430. En fin, Diego Hurtado había triunfado y sus rivales fueron dirigiendo su mirada hacia Huete, sólo que el triunfo no fue completo. Tiene razón José Antonio Jara cuando afirma que esto fue así porque no consiguió vincular por completo a la clase dirigente ${ }^{35}$. La persistencia de las redes clientelares orientadas hacia Acuña y la capacidad de organización del propio concejo, con arreglo a las ordenanzas promulgadas por Fernando de Antequera y confirmadas en 1423, tiene mucho que ver con ello.

En realidad, la pugna de bandos disputándose el predominio en Cuenca nunca desaparece. A lo largo de los años atravesará etapas de gran virulencia y otras de tranquilidad, del mismo modo que cambiará la dirección y la propia conformación de los grupos enfrentados, pero la competitividad yugulada a través de ellos permanece siempre viva, al mando de personajes capaces de orientar a su alrededor las relaciones clientelares y cuyo peso desborda a la propia ciudad. Así las cosas, no sorprende que en los años cuarenta sobreviniera un vuelco en la situación política, cuyos efectos, desfavorables para los vencedores de 1419, traerán elevadas dosis de violencia y perdurarán veinte años. Las claves del cambio son principalmente dos: por una parte, la llegada de Lope Barrientos como obispo de la diócesis y, casi a la vez, el conflicto que origina Rodrigo Manrique al pretender el maestrazgo de Santiago contra Álvaro de Luna, contando con el apoyo decidido de su suegro Diego Hurtado. Una vez más la inestabilidad del reino proporcionaba ocasiones para disputar el poder en las ciudades y las secuelas no se hicieron esperar, en forma de luchas callejeras, uso del fuego y hasta un cerco acaecido en 1449. La crisis conjugaba, por lo tanto, la conflictividad del país, la pugna de bandos en la ciudad y también los intereses nobiliarios en la tierra.

Ahora bien, no debemos ver en el obispo Barrientos un desinteresado paladín de la causa monárquica, lo que hace es perseguir sus propios objetivos, y si éstos consistían en controlar la ciudad, imponiéndose en ella; al mismo tiempo, buscaba la afirmación de su peso específico en el núcleo del poder regio. El obispo no era, por supuesto, un gran noble, pero sigue un comportamiento similar. Aporta a la

35 JARA FUENTE, J. A. «Vecindad y parentesco. El lenguaje de las relaciones políticas en la Castilla urbana del siglo XV», en El contrato político en la Corona de Castilla. Cultura y sociedad políticas entre los siglos X al XVI, Madrid, 2008. 
ciudad guerreros e influencias cerca del rey, atrae a buena parte de los notables locales con todo lo que eso implicaba y consigue imponerse durante largo tiempo. La actuación del prelado en Cuenca personifica la interacción entre diversos poderes que es característica del mundo bajomedieval: la Iglesia, a la que pertenece; el concejo que controla; la monarquía, a cuyo lado permanece siempre; incluso cabría añadir la vertiente linajística y nobiliaria.

Aunque las hostilidades de 1447-50 dejaron profunda huella en el recuerdo de las gentes, en la década de los sesenta reaparecen episodios, igualmente de gran dureza, al compás del acontecer político-militar del reino. Los Mendoza de Cañete, formando junto a los contrarios al rey, vuelven a presionar sobre la ciudad y lo hacen de nuevo con abundantes efectivos militares. Llegó a haber un cerco, pero al poco las cosas cambiaron. Efectivamente, en 1465 el obispo fue secuestrado en Belmonte por iniciativa del marqués de Villena. A los pocos días llegó Juan Hurtado de Mendoza precedido por una carta real que le ordenaba permanecer en ella para su defensa, junto a Pedro Barrientos y el provisor de la Iglesia. El noble había virado radicalmente y el trono necesitaba asegurar la ciudad en aquellos momentos de turbación. A partir de entonces Juan Hurtado proporcionó a la ciudad la organización del dispositivo de defensa y, a la vez, sus contactos y posibilidades de diálogo, tanto con el rey como con otros nobles de las inmediaciones. El obispo volvió a ser guarda mayor una vez liberado, pero ya no hay discordias y se puede comprobar que el concejo no tiene otra opción que orbitar alrededor de Juan Hurtado. Cuando el prelado murió seguía habiendo abundantes desterrados, porque eran muchos los allegados al marqués de Villena, pero el nivel de agresividad en las calles disminuyó, al tiempo que en la tierra se llega a ver a Honorato de Mendoza, hijo del cabeza de linaje, actuando arma en mano en defensa de los intereses de la ciudad. En diciembre de 1474 ambos personajes, Juan Hurtado y Honorato, y tras ellos la justicia y regimiento, proclamaron a la reina Isabel. Pareciera que su posición era inexpugnable y como en otros tiempos los Mendoza de Cañete habían alcanzado la supremacía, Al igual que entonces, se plasma en el desarrollo de funciones militares y en la dignidad de guarda mayor, pero las redes sociales y las relaciones de poder eran muy complejas y en absoluto pudieron controlarlas más que en parte. Además, cuando los soberanos se afirmaron, tras su triunfo bélico, buscaron apoyarse principalmente en los oficiales reales e incluso llamaron en algún momento a Andrés Cabrera ${ }^{36}$.

${ }^{36}$ QUINTANILLA RASO, M. C., «Marcos y formas de proyección de la nobleza conquense en su entorno urbano y territorial", en El Tratado de Tordesillas y su época. Congreso Internacional de Historia, I, 1995, pp. 137-38. Para los datos del acontecer político de Cuenca ver DíAZ IBÁÑEZ, J., Iglesia, sociedad y poder en Castilla. El obispado de Cuenca en la Edad Media (Siglos XII-XV), Cuenca, 2003, pp. 581-99; ORTEGA CERVIGÓN, J. I., «Relaciones de poder entre la monarquía y la nobleza conquense en época Trastámara: los episodios bélicos», Studia Academica, 15, 2009; ORTEGA CERVIGÓN, J. I., «Lazos clientelares y bandos nobiliarios conquenses...»; QUINTANILLA RASO, M. C., «Política ciudadana y jerarquización del poder. Bandos y parcialidades en Cuenca», E. E. M., 20, 1997; así como mis trabajos «Violencia y pugna política. Estudio de sus repercusiones en el mundo urbano a través del caso de Cuenca (siglo XV)», Studia Historica. Historia Medieval, 30, 2012, pp. 137-62, 2012; y «Violencia 
Características similares en cuando a la insistencia de un linaje dominante en hacerse con el poder, así como en la reiteración de la competitividad, se encuentran también en la urbe cabecera de la red urbana regional. Ya hemos indicado que en Toledo, al comenzar el siglo XV, se impone la familia Ayala. Para ello utilizaron dos herramientas principales: la alcaldía mayor de la ciudad y la disponibilidad de una amplia red de allegados, que es la consecuencia de su capacidad para orientar a su favor una parte importante de los entramados socio-políticos. De este modo, situándose por encima de los linajes aristocráticos que hasta entonces tenían mayor predominio en la ciudad, Pedro López de Ayala y sus sucesores ejercen una verdadera tutela de la acción política y, llegado el caso, actúan con dureza sobre los díscolos. Teniendo en cuenta los ingredientes protocolarios que incluye el cargo de alcalde mayor, vienen a ser la viva personificación de la autoridad y el prestigio.

A lo largo de los años, unas veces junto a los infantes de Aragón y otras del lado de Álvaro de Luna, mantienen una posición claramente dominante en la ciudad, apenas oscurecida por algunos momentos de debilidad a consecuencia de los avatares del reino. Sin embargo, Toledo era una ciudad grande, socialmente muy compleja, y nunca fue posible coagular a toda la élite en torno a una casa nobiliaria. Más aún teniendo en cuenta que los procesos de ascenso social fueron muy importantes en la época. Siempre hubo opiniones contrarias y la preservación de tan ventajoso lugar por fuerza pasa por una lucha permanente que viene a mostrar, una vez más, el carácter faccioso y competitivo de la sociedad política urbana en Castilla. De esta suerte, si los años treinta y gran parte de los cincuenta presentan una mayor tranquilidad, en 1445 , tras la batalla de Olmedo, salen a la luz las referidas opiniones contrarias. La llegada en este contexto del asistente Pero Sarmiento no aporta equilibrio y pacificación sino, por el contrario, una actitud abiertamente contraria a los intereses del clan Ayala. Es bien conocida la rebelión de 1449 y sus vertientes anticonversas ${ }^{37}$, pero, en realidad, no deja de ser una manifestación de la pugna por el poder que venimos tratando. Sarmiento encabezaba un bando, acaso mal definido pero claramente orientado al desplazamiento de los Ayala. Como se sabe, al final y tras abundantes dosis de violencia, Sarmiento tiene que abandonar la urbe dando al traste con sus aspiraciones.

Poniendo su atención en la configuración de los bandos implicados en la pugna política toledana, Palencia Herrejón ${ }^{38}$ ha distinguido una primera y larga etapa que

\footnotetext{
y señorialización del territorio realengo en el siglo XV. Datos y consideraciones en el caso de Cuenca», todavía inédito. Sobre los enfrentamientos políticos en los años posteriores, DIAGO, M., "La incidencia de los conflictos banderizos en la vida política de las ciudades castellanas a fines de la Edad Media: e caso de Cuenca", Hispania, 233, 2009. El marco social y político de la ciudad en GUERRERO NAVARRETE, Y. y SÁNCHEZ BENITO, J. M., Cuenca en la Baja Edad Media: un sistema de poder urbano, Cuenca, 1994, y JARA FUENTE, J. A., Concejo, poder y élites. La clase dominante en cuenca en el siglo XV, Madrid, 2000.

${ }^{37}$ BENITO RUANO, E., "La 'Sentencia-Estatuto» de Pero Sarmiento contra los conversos toledanos", Revista de la Universidad de Madrid, VI, 1957.

${ }^{38}$ PALENCIA HERREJÓN, J. R., Ciudad y oligarquía de Toledo..., pp. 708-9.
} 
califica como de formación, en la cual un sector está claramente encabezado por los Ayala mientras que el otro es oscilante y carece de dirección permanente. Después vendría la confrontación entre Ayala y Silva, los bandos clásicos. Como en todo el país, los años sesenta presentan en Toledo un grado muy elevado de conflicto que se prolonga hasta 1475. Para entonces la familia Silva había conseguido edificar en su entorno un conglomerado de relaciones con suficiente solidez como para disputar la primacía a la sombra de la inestabilidad, y los acontecimientos se suceden con rapidez. Desde el estallido de 1467, una vez más con componentes anticonversos y que tras no poco sufrimiento terminó en la expulsión del conde de Cifuentes, hasta que éste, adueñado de la urbe, proclama a la reina Isabel, apartando a Pedro López de Ayala y los suyos. Ciertamente, en estos años se despliega una lucha de bandos típica ${ }^{39}$ mediante facciones dotadas de gran solidez, y cuando unos logran imponerse desalojan a los otros y éstos combaten cuanto pueden desde fuera de la ciudad. En 1475 las nuevas condiciones políticas y el desgaste originado por tanto litigio, permiten el regreso de los expulsados y el pacto, incluyendo un cierto reparto de los altos cargos locales que venía a favorecer al conde de Cifuentes. Más tarde, la alcaldía mayor pasará a manos de un hombre de la reina, Gutierre de Cárdenas, totalmente ajeno a las cuitas del pasado ${ }^{40}$.

\section{LOS NOBLES, LAS INSTITUCIONES URBANAS Y LA TOMA DE DECISIONES}

Años antes de la muerte del canciller Ayala, su hijo, Pedro López, recibió el cargo de alcalde mayor de Toledo, que tenía el padre desde la época de Pedro I. Para él, personalmente, y para su linaje a lo largo de los decenios subsiguientes, tan alto cargo suponía mucho, nada menos que encabezar formalmente la organización municipal, con funciones que no se limitaban a la justicia sino que, como máximo representante de la ciudad, le permitían intervenir directamente, y con verdadero peso, en la toma de decisiones ${ }^{41}$. Cierto es que los alcaldes mayores no aparecen a menudo en la documentación en el ejercicio de su oficio - y si lo hacen suele ser en materia de orden público- pero esto no debe engañarnos. La

39 Enfrentamiento de partidos prototípico, afirma LÓPEZ GÓMEZ, O., «Claves del sistema de pacificación ciudadana desarrollado por los Reyes Católicos en Toledo (1475-1485)», E. E. M., 27, 2004, p. 168

40 Las siguientes obras me han servido de apoyo en el repaso que hemos hecho: FRANCO SILVA, A., El condado de Fuensalida..., Cádiz, 1994; LÓPEZ GÓMEZ, O., «Claves del sistema de pacificación ciudadana..."; del mismo autor el libro titulado Los Reyes Católicos y la pacificación de Toledo...; también la tesis anteriormente citada de PALENCIA HERREJÓN, J. R., Ciudad y oligarquía de Toledo..., y del mismo autor Los Ayala de Toledo: desarrollo e instrumentos de poder de un linaje nobiliario en el siglo XV, Toledo, 1995. Los acontecimientos políticos en E. BENITO RUANO, Toledo en el siglo XV. Vida política, Madrid, 1961.

41 FRANCO SILVA, A., lo considera «la pieza clave con la que todo poder que necesitase controlar la importante ciudad del Tajo tenía necesariamente que contar», El condado de Fuensalida..., p. 55. Sobre el cargo, PALENCIA HERREJÓN, J. R., Ciudad y oligarquía de Toledo..., pp. 209 y ss. Algunas observaciones sobre el reflejo que tiene en las ordenanzas toledanas en MOROLLÓN HERNÁNDEZ, P., «Las ordenanzas municipales antiguas de 1400 a la ciudad de Toledo», E. T. F., 18, 2005, pp. 396, 401, etc. 
alcaldía mayor otorgaba poderes concretos, además de honor y dinero ${ }^{42}$, ofreciendo una magnífica atalaya desde la que atraer gentes y estar presentes en la vida pública.

En los primeros pasos del siglo XV al lado de Pedro López de Ayala figuraba, como segundo alcalde mayor, Juan Carrillo, cuyo linaje perdió su línea principal masculina y quedó íntimamente unido al suyo; y Pedro Carrillo era el alguacil mayor. Después, el alguacilazgo que hemos mencionado pasó a manos del conde de Alba y finalmente se venderá en 1471, precisamente a otro personaje del tronco parental Ayala. Es pues indudable que la impronta nobiliaria en las instituciones no podía ser mayor y se traducía en las formas de actuar del gobierno urbano y, más concretamente, en que un linaje ocupaba una posición de neto predominio. Como no podía ser de otro modo, las alternancias que se derivan de la conflictiva vida política toledana repercuten en el ejercicio de estos cargos, pero no es este el momento para tratar sobre esto, lo que por el momento hay que resaltar es que siendo grande el honor que confería a sus ocupantes ${ }^{43}$, tenía una dimensión práctica clara y efectiva. Al final de la centuria la alcaldía mayor ya no estaba en manos de un Ayala sino de Gutierre de Cárdenas, aquéllos se habían quedado con el alguacilazgo mayor, y la alcaldía mayor de las alzadas era para un miembro del linaje Silva, rival durante tantos años. Tal es el reparto que se produce en las condiciones propias del reinado de los Reyes Católicos.

Esta presencia tan inmediata en las instituciones gubernativas a través de los altos cargos de la justicia tiene mucho que ver con la específica configuración de las mismas en el caso concreto de Toledo y ciudades andaluzas pobladas a su fuero, por lo cual no se observa en otras partes de la región ${ }^{44}$. En Guadalajara, cuyo concejo se organiza de manera bien distinta, desde la época de Pedro González de Mendoza cayeron en sus manos los oficios de la justicia, y ulteriores documentos de 1444 y 1464 vinieron a concretar dicha concesión real. Se trataba de la alcaldía de las alzadas, la alcaldía y escribanía de los padrones de la ciudad y tierra, y la justicia ordinaria, esto es, alcaldías y alguacilazgo. Ahora bien, esto no implicó nunca una presencia de los mencionados nobles en los ayuntamientos municipales y ni siquiera elegían siempre a los alcaldes y alguaciles, pues consta que se nombraban en el seno del concejo ${ }^{45}$. No se quiere decir con ello que care-

42318.000 mrs. al año, nada menos, en 1482. Ver PALENCIA HERREJÓN, J. R., Ciudad y oligarquía de Toledo..., p. 216. En 1419 Juan Carrillo, como alcalde mayor, al frente de los notables toledanos, pidió a Juan II a las puertas de la ciudad que jurase los privilegios de la misma, IZQUIERDO BENITO, R., Privilegios reales otorgados a Toledo durante la Edad Media (1101-1494), Toledo, 1990, pp. 245-46.

43 Tal como indica MOLÉNAT, J. P., «La noblesse tolédane du XVe siècle et ses origines...», p. 203, para sus ocupantes fue su título más honroso durante decenios.

${ }_{44}$ Quedan al margen cargos excepcionales, como el de gobernador de Toledo que responde a las especiales circunstancias de finales del reinado de Enrique IV y comienzos del de los Reyes Católicos.

${ }^{45}$ LAYNA SERRANO F Historia de Guadalajara y sus mendozas..., 1, II, pp. 146-47; MIGNOT, C., «Evolución de la estructura jurisdiccional en la región alcarreña...»; MIGNOT, C., "Le 'municipio' de Guadalajara au XVême siècle...", pp. 586-87. Sobre el nombramiento de los alcaldes puede verse en las actas municipales el siguiente acuerdo: «En la iglesia de Sant Andrés, a nueve días del mes de junio de 
cieran de valor, servían para mostrar el ascendiente de la Casa de Mendoza en el núcleo urbano, favorecía las relaciones clientelares y, de alguna manera, permitía también influir en los repartimientos fiscales.

En Cuenca la presencia nobiliaria en el concejo estaba asegurada por la guarda mayor de la ciudad ${ }^{46}$. En algún momento el titular de la misma invocó una antigüedad que venía desde la época de la conquista de la ciudad y cabe pensar que la citada guarda vino a sustituir al antiguo juez del concejo, una vez introducida la reforma regimental. Sin embargo, tan solo se certifica documentalmente su existencia a fines del siglo XIV, siendo el primero conocido García Álvarez de Albornoz. Era de nombramiento regio pero tendió a patrimonializarse en manos de los señores de Cañete y así, desde que en 1419 fue elegido Diego Hurtado de Mendoza, estuvo en manos de sucesivas generaciones de esta familia, salvo en las etapas de conflictividad de los años centrales del siglo XV. De manera que sirvió al trono para asegurar lealtades e indudablemente permitió canalizar «las ambiciones que todo linaje nobiliario local siente en el siglo XV hacia los concejos realengos de su entorno" ${ }^{47}$. En apariencia sus funciones tienen considerable extensión, pero estuvieron siempre muy mal definidas. El cargo tiene evidentes facetas militares y judiciales, llegando a penetrar en el terreno fiscal, pero la imprecisión fue siempre enorme y dio lugar a debates en cuanto se descendía a asuntos concretos. Las actividades judiciales, en particular, se solapaban con las instancias ordinarias y dejaron de ejercerse.

Siendo esto así, lo que hay que destacar en este cargo, más allá de lo dicho, son los siguientes aspectos: a) es la máxima representación del concejo, siendo citado en primer lugar en las actas; b) presenta un elevado componente honorífi$\mathrm{co}^{48}$; c) permite el acceso a los ayuntamientos, con lo que ello implica en cuanto a influir en el proceso decisorio. Por lo tanto, si las funciones que efectivamente tenían son imprecisas, incluso discutibles, y con facilidad invaden el campo de ac-

mill e quatroçientos e setenta e çinco años, Pedro Páez de Sotomayor e Ferrando Gómez de Córdova, regidores. Por fin de Juan de Santa Cruz, alcalde que fue en esta dicha çibdad de Guadalajara, que Dios aya, el qual falleció a cinco días de este dicho mes de junio, por lo qual pusieron por alcalde en su suçeçión e lugar a Rodrigo de Luçen, vezino de esta dicha çibdat de Guadalajara... e diéronle facultad conplida que use del dicho su oficio de alcaldía...». Publicado por LÓPEZ VILLABA, J. M., Las actas de sesiones del concejo medieval de Guadalajara, Madrid, 1997, pp. 195-96. No obstante, hay una carta del Marqués de Santillana al Concejo, fechada en 1465, para que se nombrase alguacil a Diego de Albornoz. Publicada por LUIS LÓPEZ, C., Fuentes Históricas de Guadalajara. Archivo Municipal de Guadalajara, III (1460-1473), Alcalá, n. ${ }^{\circ} 53$, p. 144. En este mismo volumen se hacen interesantes consideraciones sobre el nombramiento de los cargos concejiles, pp. XXVIII-XXIX.

${ }^{46}$ Sobre este cargo, ORTEGA CERVIGÓN, J. I., «Ciudad, nobleza y frontera: el oficio concejil de guarda mayor de Cuenca y Huete durante el siglo XV", en La gobernanza de la ciudad europea en la Edad Media, Logroño, 2011. También insistió mucho en las características del mismo, QUINTANILLA RASO, M. C., «Política ciudadana y jerarquización del poder. Bandos...», pp. 233-37.

47 GUERRERO NAVARRETE, Y. y J. M. SÁNCHEZ BENITO, Cuenca en la Baja Edad Media..., p. 130.

${ }^{48}$ DIAGO, M., «La incidencia de los conflictos banderizos en la vida política de las ciudades castellanas a fines de la Edad Media...", p. 691, ha insistido en los aspectos protocolarios del cargo y el valor simbólico y propagandístico que encerraban. 
ción de las justicias, no por ello se limita exclusivamente a la esfera de la dignidad. Sin perjuicio de que pudiera ofrecer determinadas ventajas materiales, lo más importante es que facilita la defensa de los intereses personales y linajísticos de los personajes que lo ejercieron, facilita también cierto control político sobre el funcionamiento concejil y pone de manifiesto el predominio que tenía el guarda mayor, pues aunque la posición de supremacía de sus titulares nunca derivaba exclusivamente de la tenencia del cargo, sino que tenía unos fundamentos mucho más profundos, el oficio viene a ser representación patente de su existencia. Es natural que hubiese muchos recelos y que consecuentemente el ejercicio del cargo suscitara a veces resistencias.

Si nos desplazamos a la cercana ciudad de Huete, donde también había guarda mayor ${ }^{49}$ encontramos a Pedro Carrillo, halconero mayor de Juan II, titulado además alcalde mayor de las alzadas de la localidad. Muerto sin hijos varones, Ya hemos visto que el oficio fue a parar a los señores de La Ventosa, hasta que Lope Vázquez de Acuña irrumpió al frente de la política de esta localidad. Tras el triunfo de los Reyes Católicos y la derrota de Lope Vázquez en el curso de la guerra civil, se entabló un largo pleito contra Alejo de Sandoval, que reclamó su derecho. En el curso del litigio el cargo estuvo en secrestación, fuera del alcance de los contendientes, recibiendo finalmente sentencia favorable Alejo de Sandoval ${ }^{50}$. Las características de la guarda mayor de Huete no se diferencian de lo que hemos visto en Cuenca. Solamente señalaremos que el citado Alejo de Sandoval siguió los asuntos municipales con cierta actividad. Noble de segunda fila al fin, es probable que viera en su presencia en el órgano concejil una fórmula para adquirir ascendiente político en la ciudad. Si para personajes más conspicuos las reuniones municipales y el discurrir de la vida administrativa no presentan excesivo atractivo, es probable que él contemplase las cosas desde otro punto de vista. Pero, a la larga, la actuación prepotente de Lope Vázquez de Acuña y la situación de vacío que hubo durante el pleito que le enfrentó a Alejo de Sandoval, produjo una fuerte oposición a este cargo en el seno del concejo. Tal vez una mayor cercanía al acontecer concejil le ofreciera ciertas garantías de cara a la perdurabilidad del mismo.

Si estos elevados honores, cabeza del protocolo oficial, estaban siempre ocupados, como hemos visto, por los hombres más relevantes de los linajes que contaban con mayor influencia y peso político, no ocurrirá lo mismo en otros puestos, cuyo valor era para los nobles mucho más variable. Efectivamente, si en Cuenca Diego Hurtado fue regidor en los siete primeros años del siglo XV, después sólo encontraremos, y tras un largo período de ausencia, a segundones del linaje ${ }^{51}$. También los Acuña entraron en el regimiento conquense -Pedro de Acu-

49 Ver mi libro Ciudad, territorio y poder..., particularmente pp. 238-40.

50 La sentencia definitiva de la Chancillería vallisoletana es de 1488, ORTEGA CERVIGÓN, J. I., «Ciudad, nobleza y frontera: el oficio concejil de guarda mayor...», p. 242.

51 La presencia de regidores que eran nobles titulados se dio en muchos sitios, especialmente en ciudades de mayor relevancia, DIAGO, M., «La participación de la nobleza en el gobierno de las ciudades europeas...", p. 796. 
ña y los dos Lope Vázquez de Acuña, padre e hijo-, traspasando el oficio el segundo Lope Vázquez a favor de Pedro de Barrientos en 1478, tras su derrota en la guerra civil. Andrés Cabrera lo traspasó enseguida a su hermano, previa negociación con el regimiento. Incluso nuestro ya conocido Pedro Carrillo de Huete fue regidor de Cuenca, al igual que Gómez Carrillo el Feo, aunque su desempeño del cargo es totalmente nulo. Pasando al segundo nivel de la jerarquía nobiliaria vemos que en el transcurso de la centuria lograron introducirse en el regimiento Gómez Carrillo de Albornoz en 1436 y Lope de Alarcón en 1458. El primero lo hizo enfrentándose con Diego García de Molina, miembro del patriciado local que pretendía obtener el lugar que tenía su padre, y el segundo ocupando un puesto acrecentado — voz y voto- para cuya aceptación por parte de los demás munícipes -entre los que no faltaron objeciones-contó con un apoyo tan fundamental como el de Juan Hurtado de Mendoza ${ }^{52}$. Es decir que uno y otro consiguieron introducirse por lo que podríamos denominar los resquicios del sistema, un sistema que no es privativo de un grupo dominante específicamente urbano.

En conclusión, atentos al caso de Cuenca, se comprueba que la más alta nobleza tiene poco interés por el regimiento. Indudablemente, contaba con otros medios para condicionar la política urbana y tampoco lo necesitaba para asegurar sus señoríos e intereses territoriales. Además, contaban con la clientela que ocupaba lugar en la institución. La alta nobleza no tiene ningún deseo de integrarse en la élite regimental porque actúa por encima de ella, definiéndose cual polos de atracción de las relaciones de poder. Por lo que se refiere a los individuos de segundo nivel, es evidente que la condición de regidor les permite ejercer un mayor influjo y, naturalmente, proteger desde allí sus intereses materiales y posiciones de poder. Para ellos el puesto podía tener cierto valor instrumental y ya hemos visto que hay un trasfondo de alianzas y un reparto de funciones que si no podemos esclarecer completamente sí hay que ponderar de manera muy especial. Como era de esperar a la vista de todo lo anterior, el absentismo de unos y otros en el ejercicio de las tareas regimentales fue muy grande, algo más reducido en el caso de un noble de segunda fila cual Lope de Alarcón ${ }^{53}$.

En Toledo un linaje tan sobresaliente como es el de los Silva sí aparece asentado en el regimiento tanto antes como después de obtener el título condal. Para ellos, al contrario que en Cuenca, no fue irrelevante estar directamente presentes en el órgano de poder municipal para favorecer sus objetivos políticos. Al mismo

52 GUERRERO NAVARRETE, Y. y J. M. SÁNCHEZ BENITO, Cuenca en la Baja Edad Media..., pp. $139-40$ y $157-60$.

53 JARA FUENTE J. A., Concejo, poder y élites..., p. 136, toma nota de la asistencia a las sesiones concejiles de los regidores conquenses de origen noble. En casi todos los casos apenas acudieron, pero hay varios -Pedro de Acuña, Gómez Carrillo el Feo, el segundo Lope Vázquez de Acuña-que nunca figuran en las actas. En algunos casos hay que tener presente para explicarlo las circunstancias de la conflictividad del reino, otros, simplemente, tenían sus principales intereses fuera de la política urbana. Este autor realiza un análisis detallado sobre el acceso a las regidurías, incidiendo en el proceso de negociación que se desarrollaba cuando cada nuevo regidor presentaba carta real de nombramiento y pretendía que se le recibiese en la institución municipal. 
tiempo, allí tenían sitio señores de vasallos de menor notabilidad, cual es el caso de Fernando Niño, que fue uno de los primeros regidores que hubo, a la vez que acrecentaba lo que podía sus bases económicas. Otros sucesores de la familia aparecerán en el transcurso del siglo, lo mismo que comprobamos si nos fijamos en los Rojas o Rivadeneira, e incluso en estos últimos aparecen a la vez dos personajes que debían ser hermanos ${ }^{54}$. Al igual que hemos indicado anteriormente, la presencia en el regimiento era para estos una forma tanto de influir como de proteger las posiciones propias en la estructura de poder, así como sus intereses señoriales en la tierra, siempre sin olvidar que todos ellos estaban envueltos en alianzas y vinculaciones que, en último término, desembocaban en los principales grandes de la ciudad. Efectivamente, todo indica que la influencia que éstos tenían en la composición del regimiento toledano es apreciable.

En el resto de los núcleos urbanos realengos de la región puede ser significativo el ejemplo de Pedro Arias Dávila y después su hijo Diego, cuya obtención de un lugar en el regimiento madrileño venía a cristalizar su inserción en el sistema concejil a través de su asentamiento en la tierra ${ }^{55}$. También en Madrid encontramos a Juan de Mendoza, al renunciar en 1488 su suegro Pedro Núñez de Toledo, señor de Cubas y Griñón ${ }^{56}$; así como también linajes locales que poseían diferentes señoríos en la tierra, como es el caso de los Zapata. Si miramos hacia Guadalajara, los Mendoza obtuvieron también puestos de regidor que nunca desempeñaron directamente ${ }^{57}$. En Huete los componentes de la institución municipal no eran vitalicios sino que se renovaban anualmente y además de los regidores había veintes con una importante participación en las tareas administrativas. En los años ochenta y noventa, tras la derrota de Lope Vázquez de Acuña, Alejo y Egas de Sandoval fueron veintes caballeros, interviniendo el primero en la fijación de mojones del espacio jurisdiccional y el segundo en un número de sesiones superior a Pedro y Esteban Coello, que también fueron veintes en distintas fases del siglo. Cabría citar en las últimas décadas del mismo a Fernando de Ribera, señor de Villarejo, como regidor, pero salvo lo dicho acerca de los dos Sandoval está perfectamente claro que unos cargos exclusivamente anuales en el seno de una institución relativamente numerosa no podían tener demasiado atractivo para personajes que contaban con otras posibilidades para estar presentes en la vida pública. En cuanto a los referidos Sandoval se refuerza la impresión de que es un

54 PALENCIA HERREJÓN, J. R., Ciudad y oligarquía de Toledo..., pp. 226-27, 605-06, 620-21, etc. También MOLÉNAT, J. P., «La noblesse tolédane du XVe siècle et ses origines...», p. 204.

55 VERA YAGÜE, C. M., «Los conflictos interjurisdiccionales como factor determinante...», p. 100. Afirma este autor: «Gracias a esta regiduría controlan y aumentan los beneficios que obtienen en la Tierra de Madrid, frente al resto de la oligarquía local». También en Talavera se podría decir algo parecido con respecto a Juan de Ayala, señor de Cebolla, FRANCO SILVA, A., «El proceso de señorialización de las tierras de Talavera de la Reina en el siglo XV. EI caso de Cebolla y los Ayala», en La fortuna y el poder. Estudios sobre las bases económicas de la aristocracia castellana (siglos XIV-XV), Cádiz, 1996, p. 165.

56 DIAGO, M., «La participación de la nobleza en el gobierno de las ciudades europeas...», p. 796.

57 MIGNOT, C., «El patriciado urbano de Guadalajara (1454-1502)», I Congreso de Historia de Castilla-La Mancha, VI, Toledo, 1988, p. 234. 
linaje muy interesado en el concejo optense, pues quizá sin posibilidades en el ámbito regional veían la acción concejil como una plataforma muy útil. En esta ciudad hemos tomado en consideración tanto a los regidores como a los veintes, por cuanto desarrollaban unas actividades bastante intensas. En lugares como Cuenca se elegían cada año en el seno de las parroquias determinados cargos forales que correspondían a los caballeros y alguna vez llegaron a manos de señores de vasallos, cual es el caso de Diego Hurtado de Mendoza o Lope Vázquez de Acuña. Nada representaban para ellos estos puestos anuales y ni que decir tiene que inmediatamente se ponían en manos de lugartenientes ${ }^{58}$.

En el acta correspondiente a una de las sesiones celebradas por el concejo de Guadalajara en el mes de mayo de 1454 se dice lo siguiente: «A este dicho ayuntamiento vino el señor marqués e la fabla que ende su merçed fizo fue que algunas vezes en esta villa avía seydo platicado e altercado que sería bien que el agua del Sotillo se truxiese... Lo qual dixo que sería mucho honrroso e provechoso a la dicha villa e aún porque a su casa yva poco agua e querría, si ser pudiese, acresçentar más. Por ende que les rogava, así por lo que dicho avía como por servicio suyo, quisiesen entender e dar orden en ello por manera que el fecho viniese... En conclusión en lo qual dixo que todos debían e eran obligados de contribuyr, así caballeros e escuderos como común de la villa e tierra, e que así mesmo su merçed quería ayudar en ello». A continuación, "después de ydo el señor marqués de la dicha cámara todos los sobredichos platicaron en el dicho negoçio... E todos juntamente e de una voluntad e concordia dixeron que les plazía e eran plazenteros de poner en obra lo quel dicho señor marqués los dizía, lo uno por ser tanto honrroso e conplidero a la dicha villa, lo otro porque farían en ello placer e servicio al dicho señor marqués... ${ }^{59}$. El texto no puede ser más significativo, sobre todo si se recuerda que el marqués de Santillana no tenía ninguna función municipal, lo que tenía era ascendiente, autoridad por todos reconocida. De esta manera propone, y lo hace presente en la cámara donde tiene lugar la sesión, alega la conveniencia y honor de la ciudad, y la suya propia, ofrece ayuda y reclama la contribución de toda la sociedad para financiar la obra. Todos escuchan, no hay debate, y terminada la declaración el noble se marcha. No es, en fin, una sugerencia, es una orden, dada con la solemnidad que es propia del personaje. Después solo quedaba —en un ambiente de completa concordia— organizar la tarea técnica.

Puede alegarse en este punto la excepcionalidad del caso de Guadalajara y se puede significar cómo desde Pedro González de Mendoza estaba entregada a ellos de una manera que no encuentra paralelos exactos en ningún otro lugar. Sin embargo, debemos señalar que estas intervenciones personales y directas en la

\footnotetext{
${ }^{58}$ Ver JARA FUENTE J. A., Concejo, poder y élites..., pp. 202 y 378. Muestra en esta última página cómo para Luís Hurtado de Mendoza servir uno de estos cargos, la almotazanía, podía considerarse infamante.

59 LÓPEZ VILLALBA, J. M., Las actas de sesiones del concejo medieval de Guadalajara...», pp. 99-101.
} 
vida municipal no son frecuentes, ni siquiera en Guadalajara. Ciertamente podemos encontrar en ella otros ejemplos, especialmente en asuntos de carácter honorífico y protocolario, e incluso requiriendo que se respetasen los comunales y hasta reprendiendo a los regidores otras veces ${ }^{60}$. Pero, en realidad, la tutela que los sucesivos dirigentes del clan Mendoza ejercían en la ciudad derivaba más bien de la autoridad por todos reconocida y, por supuesto, de la amplia disponibilidad de allegados del todo predispuestos a su voluntad. De esta forma, el noble aparece al frente de la ciudad jerárquicamente organizada.

En Toledo y Cuenca, donde ya sabemos que existían alcaldías mayores o guardas mayores, se puede ver ocasionalmente a sus titulares desempeñando directamente tareas derivadas de sus altos cargos, particularmente en Toledo y en materia de orden público ${ }^{61}$. Ya sabemos que no es algo habitual y además hay un alto grado de ambigüedad, de manera que cuando se acude a estos mismos personajes no es por tratarse de altos responsables en las instituciones sino por ser hombre "onrado e poderoso e cabdaloso».

En Huete, durante la época del halconero Pedro Carrillo - que fue guarda mayor y alcalde de las alzadas - hay varios testimonios que evidencian intervenciones directas del noble en materias municipales, o al menos su presencia en acuerdos y actos solemnes. Efectivamente, en las primeras décadas del siglo XV, Pedro Carrillo, al igual que había hecho su padre, desplegó una gran actividad en la ciudad, no solo en su condición de guarda mayor sino en los más diversos campos de la vida pública. La documentación optense es limitada y no siempre resulta elocuente, sin embargo nos permite encontrarlo interviniendo en procesos de delimitación del término jurisdiccional ciudadano, representando a los caballeros en contienda con los pecheros y, entre otras cosas, actuando como testigo en diferentes negocios jurídicos importantes. Algún otro miembro del linaje participaba también en esta clase de asuntos. Comprobamos pues que no son actuaciones regulares sino esporádicas y, una vez más se hacen sobre la base del ascendiente local, verdaderamente considerable y sin oposición, que convertía al referido personaje en casi imprescindible ${ }^{62}$.

Por lo tanto, las intervenciones inmediatas en tales o cuales asuntos concejiles para condicionar la decisión final, si no están ausentes tampoco son realmente abundantes, sólo que, por lo general, ni siquiera hacían falta y es muy probable que la conveniencia de impulsar ciertas obras o bien el orden público sean las

60 LAYNA SERRANO, F., Historia de Guadalajara y sus mendozas..., I, 2, p. 194, menciona un acuerdo sobre las ropas que los representantes de Guadalajara debían llevar para ir a prestar acatamiento a la reina Isabel: «que lo platiquen con el señor marqués... e sy su merçed lo mandare... que lo compren los dichos mensageros e que la çibdat lo pagará». Ver MIGNOT, C., «Le 'municipio’ de Guadalajara au XVême siècle, système administratif...», pp. 587-88.

61 MOROLLON HERNÁNDEZ, P., «Las ordenanzas municipales antiguas de 1400 a la ciudad de Toledo...», pp. 396, 410, 417-18.

62 SÁNCHEZ BENITO, J. M., Las tierras de Cuenca y Huete en el siglo XIV. Historia económica, Cuenca, 1994, pp. 76-77, y Ciudad, territorio y poder..., pp. 246-48. 
materias en las que dichas intervenciones se producen con más facilidad. Ahora bien, la presencia de tan elevados señores en diferentes actos del discurrir social y político de una ciudad enaltecía y daba un mayor vigor a los eventos en los que participaban. Es natural que su protagonismo se tornase ineludible en ciertos momentos, cual por ejemplo entradas reales o, por volver a Huete, el pleito homenaje a la reina Catalina como señora de la ciudad. Entonces su asistencia en un primer lugar confiere honor y firmeza a unos eventos en los cuales la escenografía era absolutamente esencial. Nunca podemos olvidar la parafernalia que llevaba aparejada su presencia y la representatividad que todos asociaban a estos individuos.

En todo caso, la negociación a través de los contactos es una de las parcelas en las que la acción nobiliaria podía favorecer en mayor medida a los intereses ciudadanos. En este sentido, siempre se han destacado sus posibilidades para facilitar las gestiones que tenían lugar en la Corte. Si seguimos atentos al ejemplo de Pedro Carrillo de Huete sabemos que, valiéndose de su ascendiente al lado del rey, consiguió el título de ciudad en 1428 , y así lo indica el propio documento ${ }^{63}$. No sería la única vez, son varios los nobles que respaldaron la confirmación de privilegios de este mismo concejo y lo mismo se verifica una y otra vez en todos los núcleos urbanos. Seguramente sería vacuo volver a insistir en este punto, tantas veces puesto de relieve, así que ahora tomaremos en consideración la participación de nobles poniendo en juego su influencia para facilitar negociaciones con otras instancias, incluyendo miembros de su propio grupo social. Sin apartarnos de la ciudad de Huete, consta un acuerdo establecido en 1448, entre Pedro de Acuña y el concejo, sobre problemas de límites entre realengo y señorío. Lo interesante para nosotros es que las conversaciones tuvieron lugar dentro de las casas que tenía en Huete Pedro Coello, señor de Montalbo, y que en este marco privado estuvieron presentes para propiciar el trato, además del propio Pedro Coello, Gómez Carrillo de Albornoz, Gutierre de Sandoval y Álvaro de Luna, junto con los regidores y fray Juan de Alcocer, un franciscano que actuaba en nombre de Pedro de Acuña. Ambas partes hicieron vecindad siguiendo el modelo que anteriormente se había impuesto entre la ciudad y La Ventosa, que era de Gutierre de Sandoval. Este hecho viene a ejemplificar perfectamente la función intermediaria, verdaderamente imprescindible para las ciudades, que los nobles realizaban. Sin embargo, se observa en el mismo algún otro aspecto que conviene señalar. Quiero decir que en la referida reunión figuran muchos de los señores que tenían villas limítrofes con la tierra óptense, y lo que hacen es consensuar unas soluciones útiles para todos. Por otra parte, el mismo Coello fue apoderado por el concejo para pactar con Acuña sobre diferentes aspectos relativos a la implantación señorial del mismo, incluyendo agresiones entre ambas partes ${ }^{64}$.

63 Publicó el documento QUINTANILLA RASO, M. C., «Huete, la patria del Halconero...», pp. 196-97.

64 ORTEGA CERVIGÓN, J. I., «Un enclave nobiliario en la tierra de Huete: el señorío de La Ventosa...», pp. 205-06. 
Es pues claro que las relaciones que se pueden observar en las distintas localidades entre la alta nobleza más implicada en la política local y los concejos van mucho más allá de los cargos y lo puramente institucional. En dichas relaciones hay que destacar lo siguiente: a) nunca están bien definidas en derecho, b) predomina siempre la ambigüedad, c) comprobamos también que funcionan de una manera privada, sobre la base del conocimiento personal, d) y son, finalmente, muy variables, sobre la base de equilibrios políticos siempre cambiantes ${ }^{65}$.

En este contexto debemos valorar las intervenciones aristocráticas para conseguir el nombramiento de personas de su confianza en los regimientos de las ciudades. Evidentemente era una palanca particularmente útil para el afianzamiento de relaciones con personajes importantes en la ciudad y, a la vez, una forma de incidir eficazmente en la acción del concejo. En Cuenca la documentación municipal muestra a los señores de Cañete respaldando e incluso negociando directamente el nombramiento de ciertos regidores y además dieron su apoyo al acrecentamiento de su número, por encima del estipulado legalmente, pues era una manera de complacer al rey y sobre todo era una vía para colocar a allegados ${ }^{66}$.

Pero donde esto parece más evidente es en Guadalajara. Al parecer, a fines del siglo XIV, en un contexto de conflicto entre caballeros y común, el propio concejo ofreció a Diego Hurtado de Mendoza la facultad de proponer su designación, cosa que por aquellos años se repitió anualmente. Habría que preguntarse si en la conflictividad existente no tendría que ver también la influencia del propio aristócrata sobre las estructuras del poder local, además de las querellas que como en tantos otros sitios pudieran enfrentar a exentos y no exentos. Ciertamente, las ordenanzas de 1406 reconocen el derecho de intervención que estamos viendo, así que todo viene a mostrar un grado de control sobre la institución local realmente máximo ${ }^{67}$. Si la excusa era el orden en la ciudad, la realidad es más compleja y responde a la indiscutible superioridad del almirante Diego Hurtado y a la fuerte

65 Llegados a este punto haremos notar el interés que puede tener el análisis del lenguaje en el que se expresaban dichas relaciones, si bien, dicho lenguaje se ha visto casi siempre en términos de oposición entre la ciudad y los nobles. Ver al respecto, JARA, J. A., «Percepción de 'si', percepción del 'otro': la construcción de identidades políticas urbanas en Castilla (el concejo de Cuenca en el siglo XV)», A.E. M. , 40/1, 2010; del mismo autor, «Por el conosçimiento que de él se ha». Identificar, designar, atribuir: La construcción de identidades (políticas) en Cuenca en el siglo XV», Hispania, LXXI, 238, 2011.

66 ORTEGA CERVIGÓN, J. I., La acción política y la proyección señorial de la nobleza territorial en el obispado de Cuenca..., pp. 423-24 y del mismo autor «Por seruiçios muchos e buenos que me ha fecho. Los criados de las casas nobiliarias conquenses en la Baja Edad Media", A. E. M. 39/2, 2009, p. 710; GUERRERO NAVARRETE, Y. y J. M. SÁNCHEZ BENITO, «Del concejo medieval a la ciudad moderna. El papel de las cartas expectativa de oficios ciudadanos en la transformación de los municipios castellanos bajomedievales: Burgos y Cuenca», en La Península Ibérica en la era de los descubrimientos, 1391-1492. Actas de las III Jornadas Hispano-Portuguesas de Historia Medieval, Sevilla, 1997, II, pp. 1017-18.

67 MIGNOT, C., «Le 'municipio' de Guadalajara au XVême siècle, système administratif...», pp. 58687; LÓPEZ VILLALBA, J. M., «El cuaderno de condiciones del común de Guadalajara...», pp. 131-32; LAYNA SERRANO, F., Historia de Guadalajara y sus mendozas..., I, 1, pp. 136-37. 
incidencia de éste en la definición de la élite urbana. En todo caso, hubo después cambios en la configuración del concejo y no parece que los marqueses de Santillana y luego duques del Infantado nombrasen directamente ni siquiera a alcaldes y alguaciles, aun perteneciéndoles directamente estos cargos. No quiere decirse que hubiera desaparecido la influencia que tenían, es que se ejercía por medios menos explícitos, de manera que no faltan regidores unidos a ellos mediante lazos efectivos. Seguramente el marqués de turno daba el espaldarazo a muchos de los que accedían por nombramiento regio a la dignidad de regidor ${ }^{68}$.

Independientemente deben mencionarse las maniobras para, sobre la base de conveniencias tácticas, modificar la configuración de las instituciones. Aunque no sea fácil rastrear estos movimientos en la documentación, la lógica de los mismos tiene que ver con el deseo de ampliar las redes clientelares e incrementar su peso en los debates que tenían lugar en los órganos municipales. Seguramente es lo que pretendía Diego Hurtado de Mendoza en Cuenca cuando en 1442 se acordó que junto a los oficiales concejiles se reunieran hombres buenos por cada uno de los grupos siguientes: caballeros y escuderos, guisados de caballo, y pecheros y ciudadanos; modificando así la forma de los ayuntamientos concejiles ${ }^{69}$. Ya he indicado que los hilos en esta clase de actos son difíciles de seguir y encuentran su verdadera lógica en los equilibrios de cada coyuntura.

Al abandonar el ámbito de la vida municipal, pasaremos casi de puntillas por las procuraciones a Cortes, a pesar de ser perfectamente conscientes de que con alguna frecuencia fueron desempeñadas por miembros de la alta nobleza ${ }^{70}$. Efectivamente, sea como consecuencia de las muy abundantes intromisiones regias o bien por el funcionamiento de los mecanismos ordinarios de elección, la representación en Cortes ofreció buenas oportunidades a jóvenes aristócratas de brillante futuro —Diego Hurtado de Mendoza acudió por Guadalajara a las de 1390—, también acudieron individuos tan inmersos en el círculo de poder cortesano como Andrés Cabrera y, por supuesto personajes de la primera línea política de cada momento. Bien es verdad que en Cuenca hombres como Diego Hurtado de Mendoza, Juan Hurtado y su hijo Honorato no ejercieron su representación y fueron sustituidos de diversas formas ${ }^{71}$. Sin ánimo de quitar relieve a estas procuraciones, su carácter temporal nos induce a pasar cuanto antes a otros aspectos más permanentes.

\footnotetext{
68 Ver acuerdo de 12 de diciembre de 1485, publicado por LÓPEZ VILLALBA, J. M., Las actas de sesiones del concejo medieval de Guadalajara... », pp. 288-89.

69 JARA, J. A., «Sobre el concejo cerrado. Asamblearismo y participación política en las ciudades castellanas de la Baja Edad Media (Conflictos inter o intra-clase)", Studia Historica, 17, 1999, pp. $120-24$.

70 Observa su número relativamente elevado y cita ejemplos, DIAGO, M., «La participación de la nobleza en el gobierno de las ciudades europeas...", p. 801.

71 Recoge esta información ORTEGA CERVIGÓN, J. I., La acción política y la proyección señorial de la nobleza territorial en el obispado de Cuenca..., pp. 34-35. Sobre la representación conquense en las Cortes, OLIVERA SERRANO, C., «La participación de cuenca en las Cortes castellanas bajo el reinado de Enrique IV (1454-1474), I Congreso de Historia de Castilla La Mancha, VI. Campesinos y señores en los siglos XIV y XV, Toledo, 1988; y del mismo autor «Inventario de la documentación medieval sobre las Cortes de Castilla y León en el Archivo Municipal de Cuenca (1250-1500)», E. E. M., 19, 1996; también GUERRERO NAVARRETE, Y. y J. M. SÁNCHEZ BENITO, «La corona y el poder municipal. Aproximación a su estudio a través de la elección de procuradores a Cortes en Cuenca y Burgos en el
} 


\section{LA TENENCIA DE FORTALEZAS Y LA CAPACIDAD MILITAR DE LOS NOBLES TERRITORIALES}

Más atención dedicaremos a las actividades armadas de la nobleza territorial, por entender que desempeñan una funcionalidad de la máxima importancia en las cuestiones que estamos analizando. A tal fin, no podemos olvidar las fortalezas que había en las ciudades. Recordemos que dependían del rey, constituían un verdadero hito en la geografía de cada lugar e inevitablemente tenían reflejo en el entramado de poderes que se desarrollaba en cada núcleo, cuyo espacio urbano se podía controlar muy bien desde sus alturas. Más allá de lo obvio, es decir, la capacidad bélica que conferían estos castillos a quienes los tuvieran, no son menos evidentes sus contenidos simbólicos y de ostentación a los ojos de la población y de los otros poderes con relevancia en cada lugar ${ }^{72}$. Pero si tenemos en cuenta, además de lo dicho, que la tenencia de uno de estos castillos podía llevar aparejados saneados ingresos ${ }^{73}$, no será casual que con considerable asiduidad encontremos a su frente a los grandes linajes dominantes que ya conocemos. Por consiguiente, en Guadalajara ya Diego Hurtado, representante de la segunda generación Mendoza, disponía de la tenencia, manteniéndola después sus sucesores con breve intermitencia. El mismo Diego Hurtado tenía la fortaleza de Molina en 1386, antes de que pasara a su hermano Íñigo López y así a la rama de la familia allí afincada. Si en Guadalajara la pérdida del control del castillo tuvo repercusiones no pequeñas para la propia posición del linaje en la ciudad durante los años cincuenta del siglo XV, en Molina los cambios son mucho más acusados, a pesar de lo cual desde fines de los años veinte el señor de Castilnuevo, también llamado Diego Hurtado, y a continuación su hijo Pedro Carrillo de Mendoza sostendrán el control del mismo durante apreciables espacios de tiempo. Que la imponente fortificación molinesa fue para ellos una plataforma de poder clave y que no dudaron en hacer uso de ella para sus fines, resulta indudable si se tiene en cuenta que en algún momento hubo quejas cuyo fundamento consistía en que estaban apoderados de la misma y, en general, de toda la tierra. Después, el castillo permitió la inserción de la familia del arzobispo Carrillo en la política local y, finalmente, acabó en manos del conde de Cifuentes en tiempos de los Reyes Católicos. Si miramos hacia Cuenca es la rama mendocina de Cañete la que controló la fortaleza con frecuencia, a la vez que la guarda mayor de la ciudad y siempre a

siglo XV», en Las Cortes de Castilla y León, 1188-1988. Actas de la tercera etapa del Congreso científico sobre la historia de las Cortes de Castilla y León, I, Valladolid, 1990.

72 Para enmarcar la cuestión, GARCÍA VERA, M. J. y M. C. CASTRILLO LLAMAS, «Nobleza y poder militar en Castilla a fines de la Edad Media», Medievalismo, 3, 1993. Es muy amplio el contexto que ofrece la segunda autora en La tenencia de fortalezas en la Corona de Castilla durante la Baja Edad Media (relaciones de poder entre monarquía, nobleza y ciudades). Siglos XIII-XV, tesis doctoral, Universidad Complutense de Madrid, 1997.

${ }^{73}$ Lope Vázquez de Acuña cobraba 60.000 mrs. en Huete en 1465, si bien hay que tener en cuenta la dificultad del momento político. ORTEGA CERVIGÓN, J. I., «El arraigo de los linajes portugueses en la Castilla bajomedieval...», p. 78. 
tenor de los vaivenes que implica la conflictividad de la zona; y por lo que se refiere a Toledo no nos puede sorprender que desde 1407 Pedro López de Ayala, a la sazón alcalde mayor, sea también alcaide por el rey del alcázar, puentes y puertas de la ciudad ${ }^{74}$. Hay que subrayar cómo se repite la igualdad tenencia = guarda 0 alcaldía mayor, redundando la conjunción de ambas cosas en el prestigio del noble, en su fuerza y en un aspecto que tiene gran importancia en la conformación de su imagen de poder, la capacidad para imponer el orden.

Lógicamente el papel de estos edificios aumenta de manera sensible en los momentos de mayor dificultad política. Entonces, sus ocupantes tenían una baza de primera magnitud para dominar la ciudad y para hacerse valer con cierto peso en la política general del reino. Por eso el castillo se convierte ocasionalmente en un peligro para la población urbana, desde el que partían cabalgadas o se tiraban piedras como contundente argumento de las pretensiones de su ocupante. Prueba de la importancia que podía tener como baza decisiva para controlar una ciudad es la conducta que Lope Vázquez de Acuña llevó a cabo desde el que había en el cerro existente en Huete. A partir de su arriscada y bien defendida posición, el noble condicionó enteramente la vida de la ciudad a partir de mediados de siglo -antes tuvo la tenencia un personaje imprescindible en la vida local: Pedro Carrillo-, controló con dureza la actividad concejil y se hizo valer en las querellas del reino hasta su derrota en la guerra que sirvió de pórtico a los Reyes Católicos ${ }^{75}$. En esta localidad, a juicio de M. C. Quintanilla, la alcaidía es un «cargo que permitía a su titular el desarrollo de ciertas formas de poder, a veces en un grado muy intenso, en el ámbito local» 76 .

De modo que las cosas no pueden estar más claras. Las fortalezas cambian de manos con cierto dinamismo al compás de la conflictividad de un siglo difícil, pero eso de ninguna manera impide la permanencia en ellas durante largos períodos -incluso de manera hereditaria - de los linajes dominantes tantas veces repetidos. Para sus integrantes podían ser decisivas, sea como instrumento militar, sea como base para el desarrollo de influencias, o bien como prueba de enaltecimiento y honor. La tenencia no dejaba de ser una merced del rey y, una vez obtenida, la reciedumbre de los muros era la muestra más cierta de uno de los factores esenciales para entender la posición de dichos linajes: la fuerza armada y su exhibición.

Efectivamente, no cabe dudar la importancia que la fuerza tenía para los nobles territoriales. Formaba parte esencial de su imagen, resultaba clave para su prestigio y muchas veces cimentaba su capacidad de maniobra política. En el ambiente

74 SÁNCHEZ PRIETO, A. B., La Casa de Mendoza..., pp. 183-84; CORTÉS RUIZ, M. E., Articulación jurisdiccional y estructura socioeconómica de la comarca de Molina..., pp. 1199-1201; DIAGO, M., «Relaciones de poder y conflictos políticos en Molina...», pp. 129-30; FRANCO SILVA, A., El condado de Fuensalida..., p. 55.

75 Detalles sobre la fortaleza óptense y, en particular, sobre las obras de reconstrucción que en ella se hicieron a fines del siglo XV, en QUINTANILLA RASO, M. C., La ciudad de Huete y su fortaleza

76 QUINTANILLA RASO, M. C., «Huete, la patria del Halconero...», p. 187. 
de inestabilidad que es propio del siglo XV era difícil para los concejos reaccionar frente a las nada infrecuentes amenazas que se cernían sobre los propios núcleos urbanos y sobre los territorios que éstos encabezaban. Tales amenazas se reiteraron a lo largo del siglo al compás de la disputa por el poder e indudablemente presentan un grado elevado de peligrosidad, al punto que en algunas ocasiones dieron lugar al cerco de determinadas ciudades. En estos casos, y más teniendo en cuenta la extensión que tenían los alfoces, la capacidad militar que los concejos tenían en sus manos mostraba inmediatamente sus limitaciones. La movilización de los efectivos era compleja, cara y ni se podía hacer de manera generalizada ni, mucho menos, con frecuencia. Además, la fuerza con que realmente se contaba estaba compuesta por algunos caballeros locales y peones en número no excesivo, pero con un límite, cual es que en las coyunturas conflictivas parte de los citados caballeros estaban totalmente comprometidos con los grupos en liza. Por lo tanto, cuando había peligro los concejos no tenían más remedio que recurrir a sus contactos nobiliarios y sobre todo a la fuerza armada que éstos tenían. Al ritmo de las distintas alianzas que a lo largo del siglo se fueron componiendo y según los intereses y la variable posición de los señores que se movían alrededor de cada ciudad - todo lo cual sigue una dinámica tan compleja como acelerada-, los concejos buscaban el apoyo de aquellos aristócratas que en cada tesitura no formaban parte de la amenaza que en ese momento preocupaba a la ciudad, volviendo a nobles contra nobles.

En febrero de 1449 abundantes tropas con el señor de Cañete, Diego Hurtado, a la cabeza se presentaron ante la ciudad de Cuenca con la intención de cercarla. En estos momentos de angustia, cuando la agresividad alcanzaba también a la tierra, sobre todo a ciertos puntos que el señor de Cañete pretendía integrar en sus estados, se recurrió a Pedro de Alarcón para que guardase en nombre del concejo la aldea de Valera de Suso. Pasado el peligro más inminente, se decía que no quedaba en el núcleo urbano, a fin de defenderlo, más que Esteban Coello con ocho o nueve escuderos. En 1464, en una coyuntura no menos peligrosa, Pedro Carrillo de Mendoza entró por las puertas de las murallas para proteger la ciudad con sus hombres. Permaneció allí un tiempo y como la ciudad no le pagaba, tras difícil negociación, se marchó al frente de los suyos. Meses después, en la primavera del siguiente año, el obispo Barrientos fue secuestrado a su paso por Belmonte. Como quiera que este hecho afectaba claramente a la seguridad de la ciudad, pues la supremacía del prelado era indudable y además aportaba buen número de escuderos, al poco Juan Hurtado de Mendoza irrumpía en ella con el fin de garantizar la defensa de su integridad, y lo hacía precedido por una carta real que así se lo encomendaba. A su lado formaba Pedro Barrientos y el provisor de la Iglesia, ambos contando con los medios armados del obispo. Cuando murió éste, Juan Hurtado aportaba, directa o indirectamente, la mayoría de los guerreros que hacían falta. En 1469 Álvaro de Luna, señor de Escamilla, recibía poderes de la municipalidad para que tuviese la capitanía de la urbe con cuarenta o cincuenta lanzas, y en 1475 y 76 volvemos a encontrarnos con Juan Hurtado guarneciendo la ciudad, mientras se 
desarrollaban los principales hechos de la guerra civil. En fin, Cuenca sirve muy bien como ejemplo porque los datos no faltan y hablan con nitidez: en la constante inestabilidad del siglo la ciudad resiste, pero en los momentos cruciales no puede confiar tanto en su propia milicia como en la fuerza nobiliaria ${ }^{77}$.

Si nos fijamos en la identidad de los individuos anteriormente mencionados comprobamos que hay una clara diferenciación. Por una parte señores de segunda fila titulares de villas que se localizaban por los alrededores - Coello, Alarcón, Luna-, cuya forma de hacer se asemeja a una condotta. Lo que hacen es poner un número de guerreros en defensa de la urbe durante cierto tiempo y a cambio de remuneración. Por otra, Juan Hurtado de Mendoza, representante del máximo nivel nobiliario en el ámbito conquense y que cuando se pone al frente de la defensa de la ciudad lo hace de manera decisiva, afirmando con ello su superioridad, aunque tampoco olvide cobrar el estipendio de su tropa. Naturalmente, lo mismo hacía el obispo Barrientos. Por último, aunque de manera ocasional y con muy escasa efectividad, cabe añadir al marqués de Villena, vecino meridional del alfoz concejil y siempre deseoso de ejercer alguna influencia que pudiera beneficiarle para la consecución de objetivos políticos referentes al liderazgo en el conjunto del reino. Por otra parte, ya ha quedado indicado que estos servicios armados, con independencia de las implicaciones políticas que tenían, no eran gratis, siendo a menudo imprescindible recurrir a procedimientos extraordinarios de financiación y hasta negociar con el noble de turno para retrasar los pagos. Se explica entonces que la presencia de estas huestes en el interior de las ciudades nunca tenía mucha duración y si actuaban en la tierra lo hacían con una finalidad muy concreta. Discontinuidad y falta de persistencia son pues características de estas labores guerreras.

Si se sigue el conflictivo devenir del siglo XV, se percibe inmediatamente que la iniciativa militar corresponde siempre a los nobles territoriales y nunca a los concejos. Ellos son los que tienen los medios y la voluntad política. En lo que se refiere al primero de estos dos aspectos, su fuerza residía en las comitivas de escuderos y criados que les rodeaban y, en último término, en el alcance de sus clientelas. Los escuderos, prontos a echar mano a la espada, constituían una fuerza decidida y predispuesta, cuya responsabilidad en toda suerte de altercados da idea de la familiaridad que tenían con la violencia, especialmente los más jóvenes $^{78}$. De este modo, cuando el ambiente se enrarecía, los poderosos reunían gente con presteza.

\footnotetext{
77 Remito sobre estas cuestiones a mis trabajos recientes, «Violencia y pugna política...» y «Violencia y señorialización del territorio realengo...». Por supuesto, cabría encontrar múltiples ejemplos en otros lugares. Es oportuno recordar en este momento el papel al frente de las tropas urbanas que tenían los alguaciles mayores en Toledo y Andalucía.

78 Son muchas las denuncias referentes a agresiones llevadas a cabo por criados y escuderos siguiendo los intereses de sus dirigentes. A principios del siglo XV el señor de Cañete, Diego Hurtado, en pleno enfrentamiento contra su rival en Cuenca, Lope Vázquez de Acuña, reconocía que los bullicios no eran cosa nueva entre la gente de los caballeros y más estando en una ciudad y el señor ausente.
} 
En el campo, la violencia nobiliaria va desde el amedrentamiento de la población rural, que acompaña la usurpación de un determinado lugar realengo, al paso de ejércitos que participan en las muchas querellas que rodean a los reyes castellanos del siglo XV. Entre lo uno y lo otro las posibilidades son muchas, pero el modo de actuar es siempre semejante: cabalgadas, emboscadas y acciones rápidas en los pueblos. Para ello los jinetes podían contar con el acompañamiento de peones, pero lo más importante era el apoyo que proporcionaban torres y castillos. Estas fortificaciones, aunque fueran modestas, proporcionaban cobertura para esta clase de operaciones, saliendo de ellas las cabalgadas y encontrando refugio entre sus muros al retornar ${ }^{79}$. En las ciudades la morfología del enfrentamiento también responde a unos modelos que se suelen repetir. Los hechos se inician al desencadenarse peleas o mediante la agresión a personas aisladas e incluso a las casas de individuos del bando opuesto. La causa inmediata puede ser nimia pero inmediatamente se desarrollaban rápidas carreras y acudían gentes de lo más variopinto. La chispa prendía por las calles y el tumulto se desarrollaba con rapidez, como también velozmente se producían las galopadas en el campo. Si allí torres y castillos servían de plataforma, en el interior del núcleo urbano ocurría lo mismo y las recias edificaciones de los principales se constituían en referente y garantía de impunidad al concluir las peleas.

En definitiva, los enfrentamientos en los que consta el protagonismo de la nobleza no son raros y presentan una gran variación y diversos grados. A veces bastaba la mera exhibición de fuerza, mostrando las armas y escandalizando con fuertes gritos, pero en ocasiones se recurría al empleo de armas de pólvora o al uso del fuego, cuyos efectos en las calles estrechas resulta fácil de imaginar. En casos extremos la pugna conducía a la acción de verdaderos ejércitos a fin de dar un vuelco a la situación. Toledo y Cuenca suministran buenos ejemplos de ambas cosas. No obstante, sin necesidad de llegar a la lucha abierta, más o menos dura, se recurría a muchos otros procedimientos. Entre ellos, el asesinato -incluso en lugar sagrado- no es el menos importante. El secuestro constituía también una forma de presión para condicionar los procesos políticos y obtener ventaja, paralizando en su caso la marcha de las instituciones. Tales prácticas no conocían barreras estamentales y, si llegaba la ocasión, se usaban incluso contra hombres tan conspicuos como el obispo Lope Barrientos. Sin embargo, el secuestro de personalidades relevantes era un recurso bastante extremo, a diferencia del apresamiento de aldeanos o individuos del común urbano. Desde luego, no es posible ocultar la dureza de estos aconteceres, por más que incluyan elementos rituales. A fin de cuentas son los vecinos de ciudades y pueblos los que padecen en su vida cotidiana las consecuencias de unos hechos que con facilidad se podían repetir ${ }^{80}$. Sin embargo, el discurrir de los enfrentamientos, sean de la clase que sean, está siempre

${ }^{79}$ He comprobado estos extremos en mi trabajo «Violencia y señorialización del territorio realengo...».

${ }^{80}$ Así lo indicaba LADERO QUESADA, M. A., «Monarquía y ciudades de realengo en Castilla. Siglos XII a XV», en Principi e città alla fine del medioevo, San Miniato, 1996 pp. 396 y 399. 
salpicado por treguas. La negociación no falta nunca entre unos contendientes que pertenecen al mismo rango social y se conocen perfectamente.

Es muy obvio que las formas de violencia presentan gran variación y no son los nobles los únicos responsables. Pero en todo caso para ellos era un instrumento más. Por su mentalidad y educación no tenían excesivo reparo en recurrir a ella ${ }^{81}$. Desde luego, todo indica que veían en el miedo una forma de conseguir que la preeminencia que les correspondía fuera reconocida por la colectividad ${ }^{82}$. En fin, las actitudes y comportamientos que hasta aquí se han desgranado vienen a dar la razón a Solórzano, cuando afirma que «el poder, la fuerza, la autoridad y la violencia medievales eran términos sinónimos» ${ }^{83}$, siempre sin olvidar que poder y miedo, al fin y al cabo, tienen mucho que ver. Por eso se explican perfectamente en este contexto los comportamientos altaneros y la exhibición de acompañamientos armados, como parte de un ademán que acrecentaba la idea de superioridad ${ }^{84}$. En estas condiciones no sorprende en absoluto el elevado valor legitimador que fue adquiriendo la noción paz en la argumentación política y el uso que de la misma se hará al llegar al poder los Reyes Católicos ${ }^{85}$.

\section{EL PAPEL DE LA NOBLEZA TERRITORIAL EN LA CLIENTELIZACIÓN DE LA SOCIEDAD URBANA}

Muy de pasada se ha mencionado antes el grupo de criados y escuderos que rodeaba a los miembros de la alta nobleza y sus actividades armadas. Hombres de confianza al fin, desarrollaban actividades muy variadas y ocupaban puestos domésticos, administrativos y de mando al servicio del señor. Sabemos que la coherencia de este grupo es grande y, precisamente por ello, constituye uno de los principales cimientos en los que se apoya la acción nobiliaria en todos los órdenes. A tal fin, integran el séquito armado de que se rodeaba el noble, sirviendo como fuerza combativa, al tiempo que la exhibición pública del grupo permitía al noble mostrar a las claras su potencia y su prestigio. Es comprensible que los poderosos deseasen tener en su casa el mayor número posible y que se pueda ha-

${ }^{81}$ A este respecto, LÓPEZ GÓMEZ, O., «Abusos de poder y desacato a la justicia en el ámbito urbano medieval: Toledo (1085-1422)", H. I. D., 32, 2005, pp. 216-17.

82 Una versión acaso extrema de esta manera de actuar tuvo lugar en Huete durante la etapa de predominio ilimitado de Lope Vázquez de Acuña. Ya he recurrido a este mismo ejemplo para otros fines, así que valga recordar ahora que en su transcurso se extirpó cualquier opinión contraria y se recurrió indiscriminadamente a la usurpación y el abuso. Años más tarde se dijo que había obligado a firmar contratos encarcelando a los interesados y que los del concejo tuvieron que esconder títulos y sentencias que eran contrarios a los intereses del personaje. SÁNCHEZ BENITO, J. M., Ciudad, territorio y poder..., pp. 249-51, y QUINTANILLA RASO, M. C., La ciudad de Huete y su fortaleza..., pp. 17 y 18.

${ }_{83}$ SOLÓRZANO TELECHEA, J. A., «Violencia y conflictividad política en el s XV: el delito al servicio de la élite en las cuatro villas de la costa de la mar", A. E. M., 35/1, 2005.

${ }^{84}$ Alude a las actitudes altaneras QUINTANILLA RASO, M. C., "El dominio de las ciudades por la nobleza. El caso de Córdoba en la segunda mitad del siglo XV», E. E. M., 10. La ciudad hispánica durante los siglos XIII al XVI, 1987, p. 109.

${ }^{85}$ En relación con esto, la obra de LÓPEZ GÓMEZ, O., Los Reyes Católicos y la pacificación de Toledo..., y su artículo "Claves del sistema de pacificación ciudadana...». 
blar de competencia entre ellos en este sentido ${ }^{86}$. Claro que, como se ha subrayado en ocasiones, son muchos los vecinos de las ciudades que se sienten atraídos por las posibilidades que al lado de la alta nobleza podían encontrar de esta gui$\mathrm{sa}^{87}$. Algunos de estos vecinos ocupaban un estrato elevado en la sociedad urbana y, contando con el apoyo de sus señores, no fueron pocos los escuderos y criados que alcanzaron lugares de diversa importancia en la organización concejil. Así que podemos introducirnos de esta manera en el mundo de las clientelas.

Una visión meramente superficial de la realidad política urbana en nuestra zona de estudio, inmediatamente muestra que en Toledo o en Cuenca la irrupción de los grandes linajes polarizó a su alrededor a las élites locales. La alta nobleza se convertía así en el centro de las relaciones de poder desplegando un denso entramado de vinculaciones personales que atravesaban de arriba abajo toda la escala social, desde los notables más vinculados a las instituciones hasta individuos claramente inmersos en el submundo de la marginación ${ }^{88}$. La pugna por el poder conforma el escenario que da vida a estos procesos de clientelización, no solo importantes para las relaciones políticas sino para la propia configuración de la sociedad urbana del siglo XV. Por eso la capacidad para desarrollar las acciones violentas que antes veíamos tiene mucha importancia en el impulso de estos procesos $^{89}$. Así pues, los grandes condicionan a su favor la organización de la sociedad política llevando su influencia a lo largo y ancho de la ciudad e instrumentalizando en lo posible a buena parte de sus componentes. A cambio, muchos vecinos identifican en el brillo de los poderosos su propio horizonte de promoción social y, al mismo tiempo, encuentran de esta manera una cierta garantía de seguridad, absolutamente necesaria en un entorno tan conflictivo.

Las clientelas son parte de la vida urbana y no sólo asunto de los grandes. Para cualquier personaje situado en puestos de decisión eran imprescindibles, prácticamente como sinónimo de autoridad y ascendiente social. Por lo tanto, los ricoshombres se be-

${ }^{86}$ Ver sobre el tema GERBET, M. C., «Nobles et clients dans le Royaume de Castille: criados et allegados en Extrémadure dans les années 1500", en Carlos V. Europeísmo y universalidad, Madrid, IV, 2001, pp. 337-45. Ofrece un marco general BECEIRO PITA, I., «Criados, oficiales y clientelas señoriales en Castilla (siglos XI-XV)», Cuadernos de Historia de España, LXXV, 1998-99, pp. 59-84. En la región que estudiamos ha reunido numerosos datos al respecto ORTEGA CERVIGON, J. I., «'Por seruiçios muchos e buenos que me ha fecho'. Los criados...». En relación a los Mendoza de Guadalajara, SÁNCHEZ PRIETO, A. B., La Casa de Mendoza..., especialmente pp. 253-54.

${ }^{87}$ Lo ha señalado expresamente ASENJO, M., "Oligarquía y relaciones de poder en Soria a fines del siglo XV», en La Península Ibérica en la era de los descubrimientos, 1391-1492. Actas de las III Jornadas Hispano-portuguesas de Historia Medieval, Sevilla, 1997, II, p. 1048.

${ }_{88}$ Es lo que viene a decir QUINTANILLA RASO, M. C., «Integración nobiliaria, violencia y faccionalidad en tiempos de Juan II», en El marqués de Santillana, 1398-1458: Ios albores de la España Moderna. El hombre de estado, Hondarribia, 2001, p. 104. Es significativo el dato siguiente: en 1430 el concejo conquense prohibía al alguacil que se sirviese de los rufianes que tenían Lope Vázquez de Acuña, Diego Hurtado de Mendoza y el obispo. Puede verse en JARA, J. A., «La 'nobilización' de un concejo en el siglo XV: Cuenca y los Hurtado de Mendoza», en La Península Ibérica en la era de los descubrimientos, 1391-1492. Actas de las III Jornadas Hispano-Portuguesas de Historia Medieval, Sevilla, 1997, II, p. 1034.

89 Tal como ha señalado LÓPEZ GÓMEZ, O., «Abusos de poder y desacato a la justicia...», p. 217. 
neficiaron sobremanera de unos mecanismos cuyos principales vectores fueron capaces de atraer. Al fin y al cabo las condiciones de un entorno muy competitivo y las dificultades de la obtención y mantenimiento de posiciones de dominio llevaban en muchos casos a las élites locales a buscar la sombra de los grandes. Claro que en el grupo dirigente urbano nadie se engañaba y todos percibían que los señores tenían sus propios intereses y competían con ellos especialmente en lo que toca a la explotación de la tierra. En todo caso, no pensemos solamente en los notables, ya hemos indicado que las vinculaciones penetran muy profundamente en el tejido social y son muchos los que compartían estas expectativas de promoción ${ }^{90}$. Podemos comprobarlo claramente en la élite del común.

Llama la atención la capacidad de resistencia que tienen estas redes una vez solidificadas en torno a un noble dominante. Como no podía ser de otro modo, los acontecimientos y, en definitiva, el triunfo o la derrota, afectaban a los seguidores y no en último lugar a los más destacados socialmente. De esta suerte, el discurrir de las cuitas político-militares obligaba con alguna frecuencia a marchar tras el líder, dejando atrás durante un tiempo familia y hacienda, viéndose obligados a hacer la guerra a sus vecinos a fin de recuperar la posición perdida en la urbe. En tan difíciles circunstancias se comprobaba la permanencia y solidez de los vínculos que unían a unos y otros, cuyo aguante, por lo general, es más que considerable.

El análisis de las relaciones que componen tan tupidas redes es sumamente complicado y desborda con mucho lo que podemos hacer en este artículo. Se ha distinguido entre los vínculos que tienen carácter permanente -como es el caso de escuderos y criados - y los coyunturales que podrían unir a ciertos allegados $^{91}$. La perduración en el tiempo tiene que ver, a su vez, con la profundidad de tales nexos, tan distinta en el caso de las relaciones de crianza y cohabitación o, en el extremo contrario, la mera concertación de intereses. Al mismo tiempo, cabría buscar toda una tipología siguiendo los sucesivos escalones jerárquicos, desde la relación que une a ricoshombres y regidores hasta la que se define con respecto a los hombres más sencillos. Sería interesante verificar todo esto en cada lugar y comprobar las líneas de fuerza, pero por el momento no iremos más allá. Sin embargo, un asunto tan importante en esta materia como son los acostamientos no puede quedar en el tintero. Sin duda se trata del sostén principal de buena parte del entramado que encabezaban los grandes. En verdad, la financiación de los mismos suponía una carga para ellos, lo que ocurre es que esos costes no impidieron su proliferación sin freno por la eficacia que el mecanismo tenía para vincular, o de alguna manera someter, a caballeros, hidalgos y hasta a los propios regidores.

90 Se ha destacado en diferentes ocasiones el atractivo que tiene para los conversos la vinculación a la nobleza. LORENZO CADARSO, P. L., «Esplendor y decadencia de las oligarquías conversas de Cuenca y Guadalajara (siglos XV y XVI)», Hispania, 186, 1994. En cuanto a Toledo, ver, entre otros, MOLÉNAT, J. P., «L'oligarchie municipale de Tolède au XVe siècle», en Tolède et l'expansion urbaine en Espagne (1450-1650), Madrid, 1991. p. 177.

91 ORTEGA CERVIGON, J. I., «'Por seruiçios muchos e buenos que me ha fecho'. Los criados...», p. 703. 
Con frecuencia las ordenanzas municipales salían al paso, especialmente impidiendo acceder a esta clase de relación a los miembros del regimiento, pero de poco valía la legalidad cuando la capacidad de atracción de los poderosos era tan grande ${ }^{92}$. Tan útil resultaba este instrumento que también se utilizaba, y con insistencia, en ciudades relativamente alejadas. Nos indica este hecho que los acostamientos se usaban también pensando en objetivos de proyección regional y, más allá, buscando obtener posiciones en multitud de lugares con miras a obtener un mayor peso específico en la política del reino. En todo caso, es norma general la ansiedad de todo personaje importante por encabezar el mayor número posible de seguidores.

En Toledo, Cuenca y Huete los fenómenos que estamos viendo estaban cristalizando en los comienzos del siglo XV alrededor de determinados linajes que hemos calificado como dominantes: Ayala -la red tejida por los Silva es posterior y se forma más lentamente-, Mendoza, Carrillo y Acuña, sin olvidar los antecedentes que se habían desarrollado con anterioridad alrededor del linaje Albornoz en el caso conquense. Después fueron varios los factores que a lo largo de la centuria favorecieron el crecimiento de las clientelas, y entre otros, los altos cargos que anteriormente hemos estudiado y las propias cuitas del acontecer político. A la vista de estos hechos hay que concluir que los procesos de clientelización se abrieron camino con rapidez. En Guadalajara se sabe bien que los sucesivos vástagos mendocinos no sólo aglutinaron a gran parte de la élite local sino que modificaron su composición al llegar tras ellos numerosos hidalgos que de la mano de sus señores pudieron instalarse en posiciones elevadas de la sociedad local y acceder a oficios concejiles ${ }^{93}$. Todo indica que llegaron a cortocircuitar el enraizamiento de una clase dominante propiamente urbana. Así que una vez más esta localidad contrasta con las anteriores en la medida en que aquí sí puede hablarse de control de la élite por parte del linaje nobiliario dominante, aunque dicho control no dejó de presentar fisuras.

Con estos mimbres se estructuraron los bandos que se disputaban el poder en cada ciudad. En el medio urbano del siglo XV la faccionalización era inevitable y constituía una de las principales líneas de fractura — que no la única - del sistema político concejil. Es sencillo comprender que cuando los nobles territoriales irrumpían en el primer plano de la política urbana, inmediatamente orientaban a su alrededor la disputa. En numerosas ocasiones se ha dicho que tales facciones o partidos son coyunturales y es verdad que su apariencia cambia con cierta facilidad, como también lo

92 Alude a la inoperancia de las disposiciones legales, SÁNCHEZ PRIETO, A. B., La Casa de Mendoza..., p. 214. Recuerda la autora que los duques del Infantado tenían privilegio de la reina Isabel para que los regidores pudieran vivir continuadamente en su casa.

${ }_{93}$ Atestiguan la llegada de dichos hidalgos, LAYNA SERRANO, F., Historia de Guadalajara y sus mendozas..., I,1, p. 136, y LÓPEZ VILLALBA, J. M., «El cuaderno de condiciones del común de Guadalajara...», p. 141. Además, MIGNOT, C., «El patriciado urbano de Guadalajara...», p. 234, y de la misma autora «Le 'municipio' de Guadalajara au XVême siècle, système administratif...", pp. 582 y 85 . A través de estos estudios se sabe que al menos el $20 \%$ de los regidores conocidos prestaban servicio directo al linaje dominante. No obstante, uno de ellos fue hombre de armas del conde de Medinaceli. 
hacen las alianzas dispuestas por los ricoshombres para conseguir los necesarios apoyos exteriores para su acción banderiza. También hay que decir que muchas veces permanecen en estado de latencia. Sin embargo, nada de esto resta importancia al fenómeno. Los bandos se explican por la propia violencia, vienen a dar cohesión a las clientelas y ofrecían los medios para, en inacabable litigio, alcanzar la cúspide de la pirámide política y después mantenerse en ella o volver a aspirar a su conquista si se perdía.

En Cuenca se asiste durante el siglo XIV al paso desde los bandos-linaje ${ }^{94}$ a los bandos-parcialidad, al ritmo de la introducción del regimiento y la implantación nobiliaria en la urbe; en Toledo no parece observarse dicha evolución. De todas formas, en la centuria siguiente, que es la que nos interesa, el resultado es al final muy parejo y no es otro que unas parcialidades, encabezadas por grandes de primera fila y perfectamente capaces de aglomerar de manera muy jerarquizada múltiples vinculaciones personales, así como intereses y adhesiones, del modo que ha quedado indicado antes ${ }^{95}$. En estas condiciones, y alternando la querella y el pacto, condicionarán el discurrir de la gobernación.

En páginas anteriores se han desgranado algunas de las herramientas que utilizan las facciones para maniobrar competitivamente. Ciertamente son variadas —violencia, presión, negociación, mediación, arbitraje, acuerdo, juramento-y se recurre a unas u otras según las circunstancias e incluso según la personalidad y aspiraciones concretas de los que están a la cabeza de cada bando ${ }^{96}$. Por lo tanto, la violencia, en la que ya hemos tenido ocasión de insistir, no es, por supuesto, la única posibilidad. Sin embargo, hay que admitir que en las condiciones del siglo $X V$ violencia, bandos y poder van íntimamente unidos, podría decirse que son indisociables ${ }^{97}$. Lo que ocurre es que con independencia de las consecuencias que todo esto tiene para la población -y que no cabe calificar como baladíes- debemos subrayar que esta clase de violencia reúne unas características que no ponen en peligro el orden social ${ }^{98}$. Es justamente al contrario y funcionalmente contribuye a la verticalidad y refuerza la jerarquía, por eso es tan conveniente a unos nobles que nunca renuncian a su uso. Encontramos aquí la causa por la cual las luchas banderizas, sucediéndose una vez tras otra, parecen no tener fin. En ningún momento fue posible extirparlas, pero, iojo!, tampoco condujeron, a pesar de su dureza, a la desarticulación de las sociedades urbanas, aunque algunas se vieran tan afectadas por los enfrentamientos armados como Toledo y Cuenca.

94 Sobre los bandos-linaje de Cuenca en las últimas décadas del siglo XIII y primeras del XIV, mi libro Las tierras de Cuenca y Huete en el siglo XIV..., pp. 63-65.

95 Es muy interesante el análisis que a partir del caso toledano hace sobre ellas PALENCIA HERREJóN, J. R., Ciudad y oligarquía de Toledo..., pp. 701 y ss.

${ }^{96}$ LÓPEZ GÓMEZ, O., «La paz en las ciudades de Castilla (siglos XIV y XV)», Edad Media. Revista de Historia, 11, 2010, pp. 127-28.

97 «Los bandos y la violencia son dos expresiones indisociables de la conflictividad urbana», ha escrito SOLÓRZANO TELECHEA, J. A., «Del conflicto al delito: la violencia en la sociedad urbana de Cantabria durante la Baja Edad Media», II Encuentro de Historia de Cantabria, Santander, 2001, I, p. 343.

98 LADERO QUESADA, M. A., «Monarquía y ciudades de realengo en Castilla...», p. 399. 


\section{LA ALTA NOBLEZA Y LAS CIUDADES DEL CENTRO PENINSULAR}

El siglo XV fue en Castilla un período dinámico y lleno de transformaciones. Desde tiempo atrás estaban perfectamente formadas las redes urbanas de la Península y de toda Europa, y para entonces las ciudades y villas actuaban como nodos centrales muy activos articulando el territorio. Con arreglo a la importancia de cada una se concentraban en ellas distintos poderes y jurisdicciones, cada uno de los cuales trataba de abrirse paso a través de un conjunto de relaciones sumamente complicado. Es en este horizonte en el que se ha intentado situar a la nobleza territorial, cuyas acciones y actitudes no pueden considerarse ajenas a un mundo, el urbano, al que en estos tiempos está plenamente incorporada. Efectivamente La huella de los nobles se observa por doquier: en la dinámica política, estructura social, paisaje urbano, instituciones y ceremonial, e incluso en las expectativas de vida. Sin embargo, no hay que confundirse, esto es así porque los grandes se insertaron en el mundo urbano y se vieron manifiestamente influidos por el mismo.

En el plano político, que es el que primordialmente hemos tratado, hay un factor común a todos los núcleos realengos situados en el centro de la Península Ibérica, alrededor del Tajo. Ese factor no es otro que el deseo imparable de los grandes linajes en el sentido de colocarse por encima de las estructuras urbanas de poder $y$, de esta manera, supeditar en lo posible la política y la vida local entera. A la postre no se trataba de otra cosa sino de situar en un linaje principal el foco de ambas cosas. Los instrumentos para conseguirlo conforman una larga lista (fuerza militar, capacidad de negociación, relaciones cortesanas, presencia en las instituciones, prestigio, ideología, clientelas, propiedades, señoríos, rentas, abusos...) y si el resultado no es el mismo en todos los lugares estudiados, la tendencia siempre es igual. Efectivamente, alrededor de 1400 habían conseguido en ocasiones con verdadera rapidez- polarizar a su alrededor a gran parte de las élites locales y convertirse en el centro de las relaciones de poder, y de esta manera contribuyeron de manera decisiva a la propia configuración de la sociedad urbana ${ }^{99}$. No obstante, hay que afirmar que la ciudad resiste y conserva su personalidad política e institucional, al igual que los notables urbanos, aunque éstos lo hagan mirando a la nobleza. Al final, tras el triunfo de los Reyes Católicos, los grandes consiguen el completo reconocimiento de sus intereses e influencia, aunque en un marco de estabilidad que contrasta con la dureza de los años anteriores y que a principios del siglo XVI volverá a romperse.

\footnotetext{
99 En estas condiciones, apunta Ladero, Ibidem., p. 396, los concejos pueden verse como perdedores, puesto que tuvieron que ceder sectores fundamentales de sus territorios y no solamente fueron incapaces de impedir desordenes y daños sino que a menudo estuvieron totalmente a merced de unas personas que se movían por encima de ellos.
} 
